\title{
Efficiency and economic feasibility of forward osmosis in textile wastewater treatment
}

\author{
Korenak, Jasmina; Hélix-Nielsen, Claus; Bukšek, Hermina; Petrini, Irena
}

Published in:

Journal of Cleaner Production

Link to article, DOI:

10.1016/j.jclepro.2018.11.130

Publication date:

2019

Document Version

Peer reviewed version

Link back to DTU Orbit

Citation (APA):

Korenak, J., Hélix-Nielsen, C., Bukšek, H., \& Petrini, I. (2019). Efficiency and economic feasibility of forward osmosis in textile wastewater treatment. Journal of Cleaner Production, 210, 1483-1495.

https://doi.org/10.1016/j.jclepro.2018.11.130

\section{General rights}

Copyright and moral rights for the publications made accessible in the public portal are retained by the authors and/or other copyright owners and it is a condition of accessing publications that users recognise and abide by the legal requirements associated with these rights.

- Users may download and print one copy of any publication from the public portal for the purpose of private study or research.

- You may not further distribute the material or use it for any profit-making activity or commercial gain

- You may freely distribute the URL identifying the publication in the public portal

If you believe that this document breaches copyright please contact us providing details, and we will remove access to the work immediately and investigate your claim. 


\section{Accepted Manuscript}

Efficiency and economic feasibility of forward osmosis in textile wastewater treatment

Jasmina Korenak, Claus Hélix-Nielsen, Hermina Bukšek, Irena Petrinić

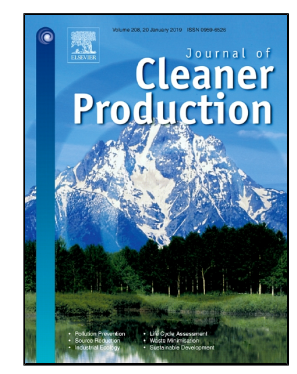

PII:

S0959-6526(18)33533-9

DOI:

10.1016/j.jclepro.2018.11.130

Reference:

JCLP 14889

To appear in:

Journal of Cleaner Production

Received Date:

02 March 2018

Accepted Date:

14 November 2018

Please cite this article as: Jasmina Korenak, Claus Hélix-Nielsen, Hermina Bukšek, Irena Petrinić, Efficiency and economic feasibility of forward osmosis in textile wastewater treatment, Journal of Cleaner Production (2018), doi: 10.1016/j.jclepro.2018.11.130

This is a PDF file of an unedited manuscript that has been accepted for publication. As a service to our customers we are providing this early version of the manuscript. The manuscript will undergo copyediting, typesetting, and review of the resulting proof before it is published in its final form. Please note that during the production process errors may be discovered which could affect the content, and all legal disclaimers that apply to the journal pertain. 


\title{
Efficiency and economic feasibility of forward osmosis in textile wastewater treatment
}

\author{
Jasmina Korenak ${ }^{1}$, Claus Hélix-Nielsen ${ }^{1,2}$, Hermina Bukšek ${ }^{1}$, Irena Petrinić ${ }^{1}$ \\ ${ }^{1}$ University of Maribor, Faculty of Chemistry and Chemical Engineering, Smetanova ulica 17, \\ SI-2000 Maribor, Slovenia \\ ${ }^{2}$ Technical University of Denmark, Department of Environmental Engineering, Miljøvej 113, \\ DK-2800 Kgs. Lyngby, Denmark \\ (jasmina.korenak@um.si,clhe@env.dtu.dk,hermina.buksek@um.si, irena.petrinic@um.si) \\ Corresponding author: Jasmina Korenak \\ Address: \\ University of Maribor, Faculty of Chemistry and Chemical \\ Engineering, Smetanova ulica 17, SI-2000 Maribor, Slovenia \\ E-mail: \\ jasmina.korenak@um.si \\ Tel: \\ +38622294474
}




\begin{abstract}
Implementing forward osmosis (FO) into textile wastewater treatment process can provide high value to an industry segment which is a large consumer of fresh water and one of the biggest polluters. In this study real textile wastewater was used as feed solution with $1 \mathrm{M} \mathrm{NaCl}, 1 \mathrm{M}$ $\mathrm{MgCl}_{2}$, blue dye mixture, and green dye mixture as draw solution in FO. Pre-determined concentrations of green and blue dye mixtures based on final desired concentrations (for further use in dyeing process), gave comparable water flux with $1 \mathrm{M} \mathrm{NaCl}$ and $1 \mathrm{M} \mathrm{MgCl}_{2}$, however, slightly higher reverse salt flux values were obtained with dyes compared to the inorganic salts. Long-term filtration followed by chemical cleaning of the FO membranes tested resulted in $100 \%$ flux recovery with negligible irreversible fouling. Membrane surface characterisation (zeta potential, contact angle, SEM and ATR-FTIR) confirmed efficient FO membrane cleaning and complete flux recovery. Rejection performance of the FO membranes for COD rejection was $>94 \%$ with up to $55 \%$ water recovery. The rejection of TDS, TSS, $\mathrm{Zn}^{2+}$, and $\mathrm{SO}_{4}{ }^{2-}$ were all $>99 \%$. Using the obtained results an OPEX/CAPEX analysis demonstrated the economic feasibility of using the FO process in textile wastewater treatment system.
\end{abstract}

Key words: forward osmosis, biomimetic membranes, textile wastewater, draw solution 


\section{Introduction}

The problem of wastewater is increasing as we face tighter regulations for discharge into sewers or surface waters. At the same time, the challenge is also how to upgrade existing technology and identify new technologies for purification of industrial wastewater for re-use. The optimal solution, which can give the appropriate quality of purified water at acceptable operating cost, is not straightforwardly identifiable as many parameters can affect the overall process. However, increasing environmental legislative demands combined with increased fresh water consumption can facilitate implementation of emerging technologies which at the current state are not yet fully mature. This may indeed be the case for the textile industry which is one of the largest consumers of fresh water and discharging large amounts of wastewater containing contaminants hazardous to the environment. Raw textile wastewaters typically have a high chemical oxygen demand (COD) and contain a wide-variety of contaminants, such as salts, surfactants, soaps, enzymes, oxidizing and reducing agents and reactive dyes (Verma et al., 2012). Most of the coloured, high molecular weight dye compounds are resistant to biological degradation, especially reactive dyes which can persist in the environment under natural conditions for 40 years or more (Hao et al., 2000, Wang et al., 2009).

The combined ability to minimize COD and colourisation is of paramount importance in order to reuse the final effluent. Thus, a combination of different techniques is required as exemplified by a combined process of coagulation/flocculation and nanofiltration for textile wastewater treatment recently presented (Liang et al., 2014, Liang et al., 2015). Membrane-based technology such as reverse osmosis (RO), nanofiltration (NF) has drawn growing interest in industrial wastewaters due to high-rejection and less production of secondary pollutants (Dasgupta et al., 2015). Recently, forward osmosis (FO) has been viewed with increasing interest due to its potential in water purification (including desalination), dewatering solutions, and wastewater treatment (Chung et al., 2012, Lutchmiah et al., 2014, Zhang et al., 2014). Mainly, FO is usually considered as a pre-treatment step to concentrate wastewater in wastewater treatment processes. Few studies were performed on textile wastewater. Han and co-workers presented the treatment of textile wastewater with combination of FO and coagulation/flocculation (Han et al., 2016). They achieved $99.9 \%$ of dye rejection and reversible membrane fouling when was performed on synthetic textile wastewater. A hybrid system of forward osmosis-membrane distillation (FO-MD) was demonstrated by Ge with coworkers (Ge et al., 2012) to concentrate textile wastewater. They established a continuous wastewater treatment process with wastewater as FO feed solution (FS) and poly(acrylic acid) 
sodium (PAA-Na) salt as a draw solution (DS), while the MD was employed to re-concentrate the PAA-Na.

Since FO is an osmotically driven process, a higher osmotic potential of DS than the FS is essential to induce a water flux. In addition, it must exhibit minimum reverse transport from the DS side to the FS side, be easily separated and re-used upon water extraction or be readily available. There have been several studies on different types of DS's, such as gas, inorganic and organic salts, magnetic nanoparticles, etc. (Ge et al., 2011, Ge et al., 2012, Ge et al., 2013). Nevertheless, the type of wastewater (FS) and the required product purity have influence on the DS selection also. However, to compete with other conventional process, FO requires high performance FO membranes and effective DS with a low energy demanding DS regeneration - if portable water is the desired end result.

Membrane fouling remains a prominent challenge for the sustained wastewater filtration of complex wastewater solutions (Valladares Linares et al., 2013, Xie et al., 2013, Zhang et al., 2014). Studies compared an osmotically driven process with a hydraulically pressure-driven process, and concluded that the membrane fouling in FO is less severe (Achilli et al., 2009) and often reversible (Mi and Elimelech, 2010a, Mi and Elimelech, 2010b, Hickenbottom et al., 2013, Zhang et al., 2014). Flux recovery after membrane cleaning is also essential due to overall FO process efficiency, therefore, efficient membrane cleaning needs to be involved to achieve constant flux. Commonly used cleaning agents are based on bases, acids, metal chelating agents, surfactants, and enzymes (Mohammadi et al., 2002). Nevertheless, proper selection of chemical cleaning agents relies on knowing the specific chemical reactions between the foulants and the cleaning chemicals.

The aim of the study was to evaluate the FO process for textile wastewater treatment and to determine the appropriate DS having minimal reverse salt flux to the FS. Mixtures of concentrated dyeing solution were tested as a DS. Therefore, no additional process was needed for DS recovery, which eliminates one of the major issues impeding the commercialisation of the full-scale FO process: lowering the energy cost of the DS recovery process. Another objective was to identify long-term performance parameters for the FO process for concentrating real textile wastewater, collected at a local textile industry in Slovenia. Rejection of specific parameters was evaluated and membrane surface characterisation of virgin, fouled and cleaned biomimetic FO membrane was performed. Economic feasibility of a sustainable and cost-effective treatment process study established two options of implementing FO process and/or coupled with RO regeneration step and the analysis indicates that FO indeed can contribute to lowering the water footprint in the textile industry in a cost-efficient manner. 


\section{Materials and methods}

\subsection{Materials and chemicals}

All chemicals and reagents used in this study were of analytical grade and used without further purification. FO Aquaporin Inside ${ }^{\mathrm{TM}}$ membranes were acquired from Aquaporin $\mathrm{A} / \mathrm{S}$ Copenhagen, Denmark.

Different aqueous DSs were used, namely $1 \mathrm{M} \mathrm{NaCl}, 1 \mathrm{M} \mathrm{MgCl}_{2}$, and additionally, chemical agents used in the production line were applied as DS. Two dye mixtures were tested as DS prepared from dyes and chemical agents (Table 1 and 2) used in production process.

Table 1. Composition of green dye mixture (based on company recipe) used as a DS.

\begin{tabular}{clc}
\hline & Dye mixture agents & $\begin{array}{c}\text { Concentration } \\
(\mathrm{g} / \mathrm{L})\end{array}$ \\
\hline \multirow{4}{*}{ Auxiliaries } & 3 \\
& Albatex DBS & 2 \\
& Alviron FLD & 4 \\
& Lyoprint RG & 8 \\
\hline \multirow{3}{*}{ Reactive Dyes } & Albatex SA 2000 & 1.369 \\
& Avitera Yellow SE & 0.51 \\
& Avitera Cardinal SE & 1.936 \\
\hline Salt & Avitera blue SE & 120 \\
\hline
\end{tabular}

Table 2. Composition of blue dye mixture (based on company recipe) used as a DS.

\begin{tabular}{clc}
\hline & Dye mixture agents & $\begin{array}{c}\text { Concentration } \\
(\mathrm{g} / \mathrm{L})\end{array}$ \\
\hline \multirow{2}{*}{ Auxiliaries } & Albatex DBS & 3 \\
& Alviron FLD & 2 \\
\hline \multirow{3}{*}{ Reactive Dyes } & Novacron Marine FN-B & 8.24 \\
& Novacron Brilliant Rot EC-3GL & 0.576 \\
& $\mathrm{Novacron}^{2}$ Gelb FN-2R181-3 & 0.32 \\
\hline \multirow{2}{*}{ Salt } & $\mathrm{Na}_{2} \mathrm{SO}_{4}$ & 160 \\
& $\mathrm{Na}_{2} \mathrm{CO}_{3}$ & 20 \\
\hline
\end{tabular}

\subsection{Experimental procedures}

Two FO experiments were conducted; firstly, different DS's were evaluated where the DS were diluted during experiment and secondly long-term filtrations with real textile wastewater as a feed were conducted with keeping the conductivity of the DS constant. Wastewater samples were obtained from local textile industry in Slovenia. 
Water flux and reverse salt flux during the experiments were evaluated using Eq. 1 and Eq. 2, respectively.

Water flux, $J_{w}\left(\mathrm{~L} / \mathrm{m}^{2} \mathrm{~h}\right)$ across the FO membrane was calculated based on volume change of FS:

$$
J_{w}=\frac{\Delta V}{A \Delta t}
$$

where:

$\Delta V$......total volume change of permeate water $(\mathrm{L})$,

A ........effective membrane area $\left(\mathrm{m}^{2}\right)$, and

$\Delta t$.......time (h).

In FSs, conductivities were measured and converted to concentrations (in $\mathrm{mg} / \mathrm{L}$ ) using a standard curve built from a series of single solutions relating conductivity and concentration. The concentration of the DS transporting to the FS was thereafter obtained directly from the standard curve. The reverse salt flux, $J_{s}\left(\mathrm{~g} / \mathrm{m}^{2} \mathrm{~h}\right)$ was determined from the concentration increase of the FS:

$$
J_{s}=\frac{c_{t} V_{t}-c_{0} V_{0}}{A \Delta t} .
$$

where:

$c_{0} \ldots . . . .$. initial concentration of the FS $(\mathrm{g} / \mathrm{L})$,

$V_{0} \ldots \ldots . .$. initial volume of the FS (L),

$c_{t}$........solutes concentration $(\mathrm{g} / \mathrm{L})$,

$V_{t} \ldots \ldots . . .$. volume of the FS at time $t(\mathrm{~L})$, and

$\Delta t$.......filtration time (h).

\subsubsection{Testing different DSs}

Filtrations were conducted with DI and real textile wastewater as feed testing four different DS, as specified in Table 5 in section 3.1. A schematic diagram of the laboratory-scale FO system is given in Fig. 1.

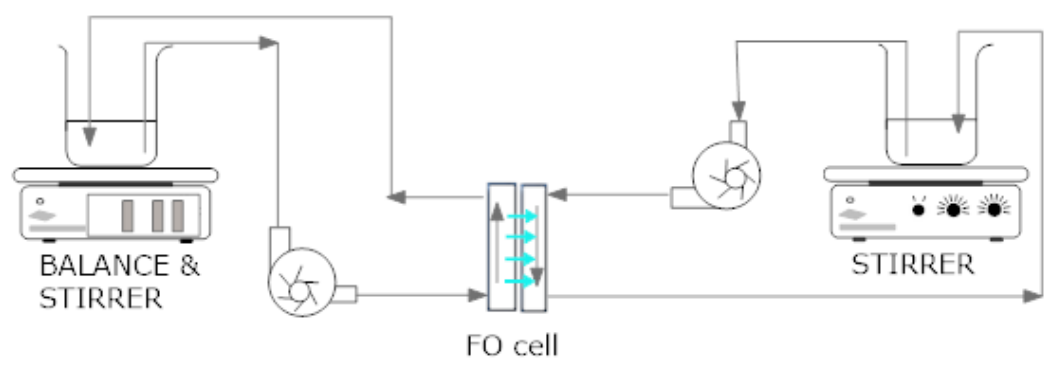


Fig. 1. Process scheme of FO experiments with diluting DS and concentrating FS.

A cross-flow membrane cell (Sterlitech Corporation, USA) with an effective membrane area of $33.15 \mathrm{~cm}^{2}$ was used. The FS and DS were circulated ( $\left.50 \mathrm{~mL} / \mathrm{min}\right)$ by peristaltic pumps. The FS tank was positioned on a digital balance (Ohaus Corporation, Greifensee, Switzerland) connected to a computer, and weight changes were recorded automatically every 30 seconds to determine the permeate water flux. The conductivity of the FS was monitored by a conductivity meter for the calculation of reverse salt flux.

The FO process with textile wastewater as FS and dye mixtures as DS were performed in batch experiments. Pre-determined concentrations of dye mixtures were selected based on final desired concentrations for the DS. Experiments were conducted with 50\% rate recovery as this up-concentrating still is within environmental regulations for discharge to the municipal wastewater treatment plant. Therefore, dye DS were prepared with initial concentrations higher than used in the actual production process, so they can be used in dyeing process after FO dilution.

The osmolality of the solutions were determined using Gonotec Osmomat 030 freezing point cryoscopic osmometer (Berlin, Germany). Osmolality is expressed in Osm/ $\mathrm{kg} \mathrm{H}_{2} \mathrm{O}$ :

$$
\text { Osmolality }=\Sigma \varphi \cdot n \cdot c
$$

and the osmotic pressure, $\pi$ of DS's was calculated via the modified Morse equation (Wilson and Stewart, 2013):

$$
\pi=\left(\sum \varphi \cdot n \cdot c\right) \cdot R \cdot T
$$

Where in Eqns.3\&4:

$R$........gas constant $(8.31447 \mathrm{~J} / \mathrm{mol} \mathrm{K})$,

$T$..........absolute temperature (K),

n..........amount of substance (mol)

c.........corresponds to the molarity of a solution ( $\mathrm{mol} / \mathrm{L})$, and

$\varphi$........osmotic coefficient (-).

\subsubsection{Long term filtrations with real textile wastewater as a feed}

In theory, water continually flows to the DS side from the wastewater side until the osmotic pressure difference cross the FO membrane reaches zero. Therefore, automatic dosing of concentrated DS was employed, to enable constant osmotic pressure on the draw side. $J_{w}$ will 
decrease due to a decreasing osmotic pressure difference, since the wastewater is being concentrate. A schematic diagram of the FO setup is shown in Fig. 2. A cross-flow filtration unit was applied with an active membrane area of $0.0195 \mathrm{~m}^{2}$. The volumetric flows of both DS and FS were $0.2 \mathrm{~L} / \mathrm{min}$ in counter-current mode through the FO cell and were constantly circulated in the setup. All experimental tests were conducted in FO mode (i.e., the selective layer facing the FS).

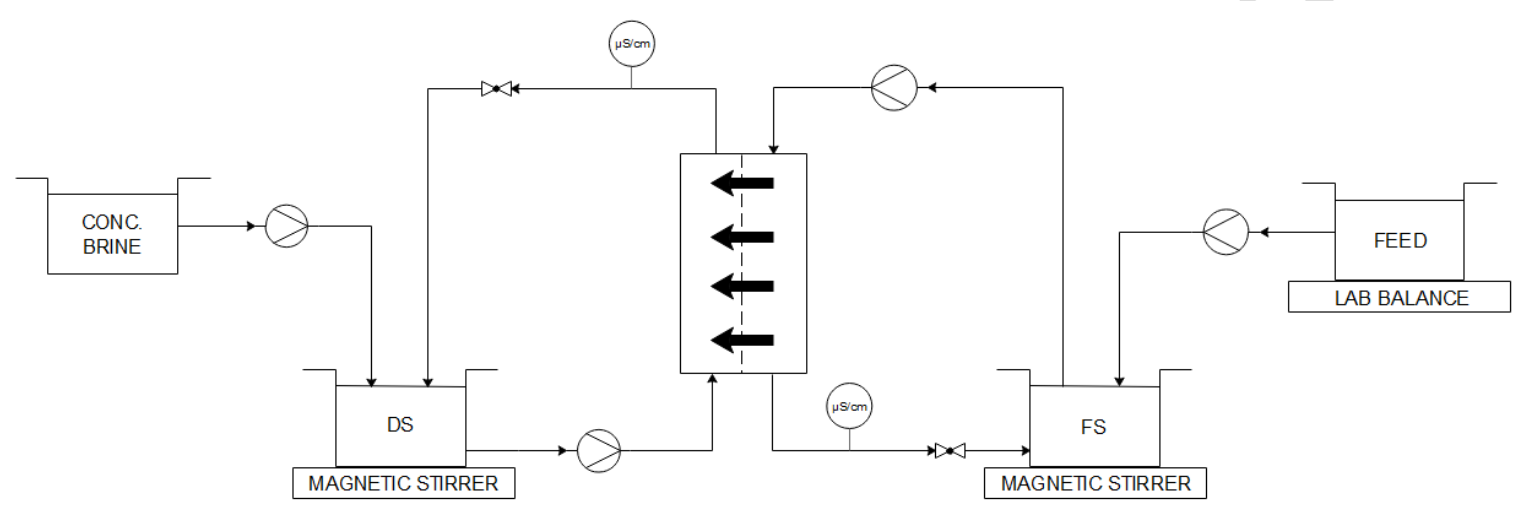

Fig. 2. Process scheme for the long-term filtrations.

The pilot unit enables the continuous adding of FS while keeping DS conductivity constant by automated adding of solution of higher concentration.

The serial resistance model is being applied to evaluate the fouling characteristics of the FO membrane. According to this model, the membrane flux, $J$ can be expressed as follows (Zhang et al., 2009):

$$
J=\frac{\Delta P}{\mu R_{t}}=\frac{\Delta P}{\mu\left(R_{m}+R_{\text {rev }}+R_{\text {irrev }}\right)}
$$

where:

$J$........membrane flux $\left(\mathrm{L} / \mathrm{m}^{2} \mathrm{~h}\right)$,

$\triangle P$......osmotic pressure difference $(\mathrm{Pa})$,

$\mu \ldots . . . . . v$ viscosity of the permeate (Pas),

$R_{t} \ldots \ldots . .$. total resistance $\left(\mathrm{m}^{-1}\right)$,

$R_{m} \ldots . . . .$. .resistance due to membrane itself $\left(\mathrm{m}^{-1}\right)$,

$R_{\text {rev }}$.....reversible fouling resistance $\left(\mathrm{m}^{-1}\right)$, and

$R_{\text {irrev }}$...irreversible fouling resistance $\left(\mathrm{m}^{-1}\right)$. 
Determination of each resistance value were done as follows (Zhang et al., 2014, Wang et al., 2016):

i) $\quad R_{m}$ : The average membrane flux in first hour of the virgin membrane; DS was $2 \mathrm{M}$ $\mathrm{MgCl}_{2}$, and FS was DI water (assuming $R_{\text {rev }}$ and $R_{\text {irrev }}$ is zero).

ii) $\quad R_{t}$ : After $21 \mathrm{~h}$ of wastewater filtration, the wastewater was replaced by DI water and fresh solution of $2 \mathrm{M} \mathrm{MgCl}_{2}$ was set as a DS. $R_{t}$ was then measured from the average membrane flux in first hour of the used membrane.

iii) $\quad R_{m}+R_{\text {irrev }}$ : Cleaning step (as described in Table 3); After cleaning, the water flux of the cleaned membrane was measured for one hour using $2 \mathrm{M} \mathrm{MgCl}_{2}$ as DS, and DI water as FS.

iv) $\quad R_{\text {rev }}$ : Was determined by subtracting $R_{m}+R_{\text {irrev }}$ from $R_{t}$.

v) $\quad R_{\text {irrev }}$ : Was then obtained by subtracting $R_{\text {rev }}$ and $R_{m}$ from $R_{t}$.

Table 3. The cleaning procedure.

\begin{tabular}{llll}
\hline Step no. & Procedure & Agent & Duration \\
\hline 1 & Washing & Cold water & $5 \mathrm{~min}$ \\
2 & Chemical cleaning at $\mathrm{pH} 11$ & $0.1 \mathrm{M} \mathrm{NaOH}$ & $30 \mathrm{~min}$ circulating at $30^{\circ} \mathrm{C}$ \\
3 & Washing & Cold water & $5 \mathrm{~min}$ \\
4 & Chemical cleaning at $\mathrm{pH} 2$ & $0.1 \mathrm{M}$ Citric Acid & $30 \mathrm{~min}$ circulating at $30^{\circ} \mathrm{C}$ \\
5 & Washing & Cold water & $5 \mathrm{~min}$ \\
\hline
\end{tabular}

The component Rejection (\%) was defined as the percentage of FS solutes retained by the membrane:

$$
\text { Rejection }=\frac{c_{d} \times V_{d} / V_{p}}{c_{f}} \times 100 \%
$$

where:

$c_{d}$.........concentration in the DS at the end of each FO test $(\mathrm{mg} / \mathrm{L})$,

$V_{d}$.......final volume of the DS (L),

$V_{p} \ldots \ldots . .$. volume of the permeate water (L), and

$c_{f}$.........compound concentration in the FS ( $\left.\mathrm{mg} / \mathrm{L}\right)$.

\subsection{Economical-feasibility study}

In this study, the total operational costs were considered to consist of membrane replacement, pump electrical cost, and draw solute cost. Other operational costs such as, manpower, 
transportation, maintenance, membrane cleaning agents and membrane disposal were excluded. In Table 4 all equations, Eq. 7 - Eq. 16 used in economic-feasibility study are presented.

Table 4. Calculations for economic feasibility studies.

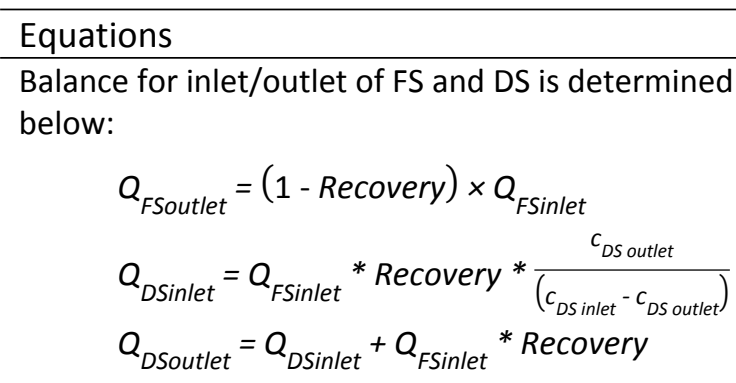

(9)

Mass balance is stated in $\mathrm{m}^{3} /$ day and calculations based on daily produced wastewater for the textile company.

$$
Q_{\text {treated }}=\frac{J W \times A_{m} \times \text { No.module } \times t}{1000}
$$

(10)

Pump power consumption is calculated with following equation, were assumed pump efficiency is $80 \%$.

$$
\text { Pump power consumption }\left(\frac{k W h}{m^{3}}\right)=\frac{p_{\text {inlet }} \times Q_{\text {inlet }}}{\eta} * \frac{t}{Q_{\text {treated }}}
$$

Number of membrane modules depends on volume of treated water in specific time and membrane area of the module, which is set to $20 \mathrm{~m}^{2}$.

$$
\text { No.membrane module }=\frac{Q_{F \text { sinlet }} \times \text { Recovery }}{J w \times A_{m} \times \text { Daily operating time }}
$$

Required RO membrane area was calculated since the membrane are per module is not set.

$$
R O \text { membrane area }=\frac{Q_{\text {treated }}}{t \times p_{R O} \times P W P}
$$

lons of salt are permeating through the FO and RO membrane and the concentration of salt passage is determined experimentally, while the total amount of salt is calculated with following two equations.

$$
\begin{aligned}
& m_{\text {salt_FO }}=J_{s} \times A_{m} \times t \times \text { No.of memb. modules } \\
& m_{\text {salt_RO }}=(1-\text { Rejection }) \times c_{\text {aver }} \times M(\mathrm{NaCl})
\end{aligned}
$$

In order to calculate the treated water in cost per $\mathrm{m}^{3}$ in relation to the invested capital, the required investment at a given interest rate, during a period equal to the estimated life of the plant needs to be included.

$$
a=I \times \frac{i \times(1+i)^{n}}{(1+i)^{n}-1}
$$

Parameters

$Q_{\text {FSoutlet }}=$ flowrate of outlet ( $\mathrm{m}^{3} /$ day) of FS

$Q_{\text {Fsinlet }}=$ flowrate of inlet $\left(\mathrm{m}^{3} /\right.$ day) of FS

$Q_{D \text { Sinlet }}=$ flowrate of inlet $\left(\mathrm{m}^{3} /\right.$ day) of DS

$c_{\text {DSoutlet }}=$ concentration of DS in outlet flow (mol/L) (RO feed),

$c_{D \text { Sinlet }}=$ concentration of DS in inlet flow ( $\mathrm{mol} / \mathrm{L}$ ) (inlet to FO)

$J_{w}=$ water flux $\left(\mathrm{L} / \mathrm{m}^{2} \mathrm{~h}\right)$

$A_{m}=$ membrane area $\left(\mathrm{m}^{2}\right)$

$Q_{\text {treated }}=$ required treated flow $\left(\mathrm{m}^{3} /\right.$ day)

$P=$ power consumption $\left(\mathrm{kWh} / \mathrm{m}^{3}\right)$

$p_{\text {inlet }}=$ Pressure inlet (bar)

$\eta=$ pump efficiency $(\%)$

$Q_{\text {inlet }}=$ flowrate of inlet ( $\mathrm{m}^{3} /$ day)

$t=$ daily operating hours $(\mathrm{h})$

$p_{R O}=$ inlet pressure at $\mathrm{RO}$, depends on osmotic pressure of DS (bar)

$P W P=$ water permeability $\left(\mathrm{L} / \mathrm{m}^{2} \mathrm{~h}\right.$ bar $)$

$m_{\text {salt_FO }}=$ salt lost through FO membrane ( $\mathrm{kg} /$ day)

$m_{\text {salt_RO }}=$ salt lost through $\mathrm{RO}$ membrane ( $\mathrm{kg} /$ day)

$c_{\text {aver }}=$ average concentration of salt between inflow and outflow (mol/L)

$M(\mathrm{NaCl})=$ molecular weight of $\mathrm{NaCl}$

$a=$ annual amortization rate

$I=$ investment

$n=$ number of amortization years

$i=$ interest rate 


\subsection{Analytical methods}

The concentration of dyes was measured according to the spectrophotometric method, using UV-visible spectrophotometer (Agilent Technologies, US). Concentration of ions $\mathrm{Zn}^{2+}$ and $\mathrm{SO}_{4}{ }^{2-}$ were determined by atomic absorption spectrophotometry (Perkin Elmer100 B, Waltham, MA, US) and ionic chromatography (Dionex CD20/Ion chromatography, Dionex-Thermo Fisher, Sunnyvale, CA, US). Chemical oxygen demand (COD) analyses were performed by the SIST ISO 6060 method with titrimetric determination, total dissolved solids (TDS) and total suspended solids (TSS) were performed by gravimetry. The osmolality of DS and FS was measured using an osmometer (Gonotec, cryoscopic osmometer, Osmomat030, Berlin, Germany). $\mathrm{pH}$ and conductivity were determined using a multi $\mathrm{pH}$ meter Multi 3410 (WTW, Weilheim, Germany) and a conductivity meter (SD 320 Con, Lovibond, Tintometer, Dortmund, Germany), respectively.

\subsection{Membrane surface characterisation}

Membrane surface measurements, namely, zeta potential (ZP), contact angle, field-emission scanning electron microscopy (SEM) analysis, and Attenuated Total Reflectance - Fourier Transform Infrared Spectroscopy (ATR-FTIR) were performed on virgin, fouled, and cleaned membrane.

ZP of membrane surfaces were measured by zeta potential using a SurPASS, electrokinetic analyser (Anton Paar GmbH, Graz, Austria). Contact angle was measured by drop shape analysis (DSA) using a Krüss DSA 100 analyzer (Hamburg, Germany). Membrane morphology was analysed by SEM using a Carl Zeiss FE-SEM SUPRA 35 VP electron microscope (Carl Zeiss, Jena, Germany). Here samples were attached to SEM holders with a double-sided adhesive carbon tape and sputtered with a thin layer of palladium, in order to convey conductivity to samples. Images were taken with an accelerating voltage of $1 \mathrm{keV}$ and at a working distance of approximately $4.5 \mathrm{~mm}$. ATR-FTIR IRAffinity-1 (Shimadzu, Japan) was used to identify the functional groups of the surface of the membrane active layer in the spectral range from 4000 to $600 \mathrm{~cm}^{-1}$.

\section{Results and discussion}


First, different DS's were evaluated in batch filtration experiments. Then long-term filtrations were performed with DS conductivity kept constant to assess flux and rejection with real wastewater as FS. Subsequently, membrane fouling and cleaning were investigated by analysing membrane surface characteristics (zeta potential, contact angle, SEM and ATRFTIR) and membrane resistances of virgin, fouled, and cleaned membranes. Finally, an economic feasibility study of the process will be presented.

\subsection{DS evaluation in batch filtration}

The driving force in FO process is a difference in osmotic pressures between FS and DS, therefore, a higher osmotic potential of the DS than the FS is essential to induce a water flux through semi-permeable FO membrane. The most common used DS are inorganic salts (Chekli et al., 2012), and among the cheapest are $\mathrm{NaCl}$ and $\mathrm{MgCl}_{2}$.

Dye mixtures are composed of several chemical agents such as auxiliaries (levelling and dispersing agents), reactive dyes and salts. The salt increases affinity of dyes towards the textile materials and is used as an electrolyte for migration, adsorption, and fixation of the dyestuff. More inorganic salt is required for dyestuffs with lower affinity.

For the filtrations, $\mathrm{NaCl}$ and $\mathrm{MgCl}_{2}$, as well as for green and blue dye mixtures have been taken as DS's. Conductivity, osmolality data as well as the osmotic pressure of all DS are given in Table 5. In order to evaluate contributions of each component (auxiliaries, reactive dyes and salts) in dye mixtures, osmolality was measured, and osmotic pressure calculated using Eq.3 and Eq.4.

Table 5. Conductivity and osmolality data for the FS, DS and components from the dyeing mixtures.

\begin{tabular}{lccc}
\hline & $\begin{array}{c}\text { Conductivity } \\
(\mathrm{mS} / \mathrm{cm})\end{array}$ & $\begin{array}{c}\text { Osmolality } \\
(\mathrm{Osm} / \mathrm{kg})\end{array}$ & $\begin{array}{c}\text { Osmotic pressure } \\
(\mathrm{bar})\end{array}$ \\
\hline $\mathrm{FSs}$ & & & \\
\hline 1. Deionised water & 0.008 & 0 & 0 \\
2. Textile wastewater & 9.6 & 0.157 & 3.87 \\
\hline $\mathrm{DSs}$ & & & \\
\hline 1. $\mathrm{MgCl}_{2}(\mathrm{MM})$ & 110 & 2.348 & 57.75 \\
2. $\mathrm{NaCl}(1 \mathrm{M})$ & 85 & 1.9079 & 47.08 \\
3. Green dye mixture & 89.7 & 1.924 & 47.48 \\
Auxiliaries & 9.83 & 0.087 & 2.147 \\
Reactive $\mathrm{Dyes}^{*}$ & 0.873 & 0.026 & 0.642 \\
$\quad$ Salt $\left(0.84 \mathrm{M} \mathrm{Na}_{2} \mathrm{SO}_{4}\right)^{*}$ & 86.1 & 1.848 & 45.60 \\
4. Blue dye mixture & 107.5 & 2.768 & 68.31
\end{tabular}




\begin{tabular}{|c|c|c|c|}
\hline Auxiliaries* & 0.487 & 0.008 & 0.197 \\
\hline Reactive dyes* & 5.03 & 0.074 & 1.826 \\
\hline $\begin{array}{l}\text { Salt }\left(1.13 \mathrm{M} \mathrm{Na}_{2} \mathrm{SO}_{4} \text { and }\right. \\
\left.0.19 \mathrm{M} \mathrm{Na}_{2} \mathrm{CO}_{3}\right)^{*}\end{array}$ & 107.5 & 2.716 & 67.02 \\
\hline Salt $\mathrm{Na}_{2} \mathrm{SO}_{4}(1.13 \mathrm{M})^{*}$ & 102 & 2.368 & 58.43 \\
\hline Salt $\left(0.19 \mathrm{M} \mathrm{Na}_{2} \mathrm{CO}_{3}\right)^{*}$ & 25 & 0.462 & 11.4 \\
\hline
\end{tabular}

*(concentration as in green and blue dye solutions, respectively)

In both dyeing mixtures, $96 \%-98 \%$ of the osmotic pressure is generated by salts. Auxiliaries and reactive dyes generate only 2.15 bar and 0.64 bar in green dye mixture, and 0.2 and 1.8 bar in blue dye mixture, respectively, which together presents $5.87 \%$ and $2.96 \%$ of total osmotic pressure in dyeing mixtures, respectively. Dye mixtures have a comparable osmotic pressure to $1 \mathrm{M} \mathrm{NaCl}$ and $1 \mathrm{M} \mathrm{MgCl}$.

In order to evaluate different DS's (selected in Table 5) a series of filtrations have been done, firstly (\#1) using DI water as a FS and secondly (\#2) real textile wastewater as FS. Average water flux, $J_{w}$ (calculated using Eq. 1), after $1 \mathrm{~h}$ of filtration and conductivity before and after the FO process using DI and textile wastewater as FS, respectively is shown in Fig. 3.

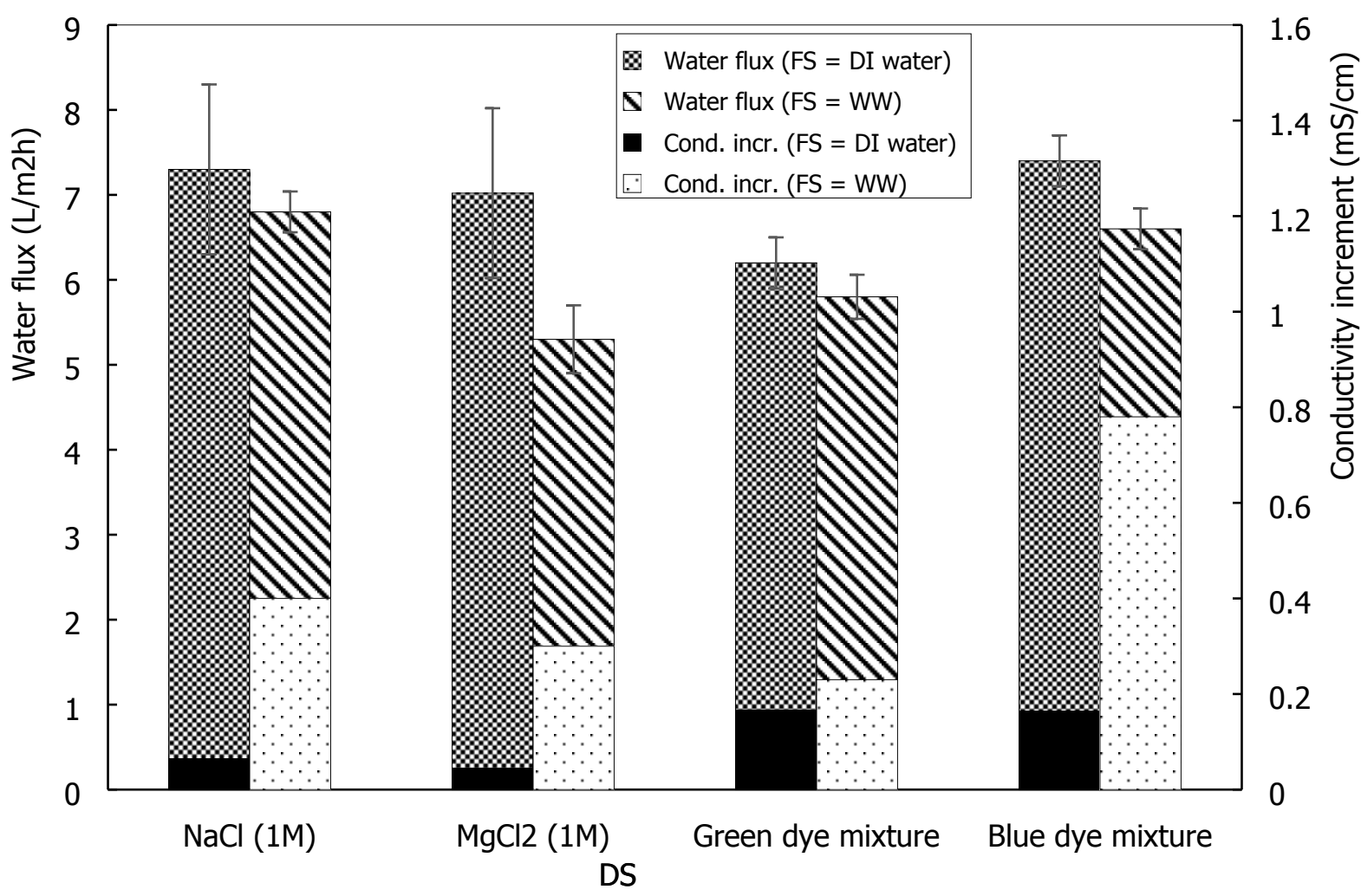

Fig. 3. Average water flux, $J_{w}$ in $1 \mathrm{~h}$ running and conductivity increment during the FO process, $\Delta \kappa$ using DI and textile wastewater as FS. 
The characteristics of FS, such as osmolality have an impact on net osmotic pressure difference. Dissolved impurities on the feed side lowered the net osmotic pressure difference as well as the water flux when compared filtrations using real textile wastewater and DI as a FS, for $6.85 \%$; $24.50 \% ; 6.45 \% ; 10.81 \%$ for $\mathrm{NaCl}, \mathrm{MgCl}_{2}$, green and blue dye solutions, respectively. Since, real textile wastewater is used for FS, conductivity increment in the FS after 1h running is presented on the secondary y-axis. The increase in conductivity in \#1 filtrations were only due to the reverse salt flux from the DS while in the \#2 filtrations, the increase is generated by the up-concentrating process as well as reverse salt flux. In the latter, the conductivity increase was the highest using blue dye mixture $(\Delta K$ is $0.78 \mathrm{mS} / \mathrm{cm})$ followed by conductivity increment using green dye mixture ( $\Delta K$ is $0.23 \mathrm{mS} / \mathrm{cm}$ ), followed by 0.3 and $0.4 \mathrm{mS} / \mathrm{cm}$ using $\mathrm{MgCl}_{2}$ and $\mathrm{NaCl}$ as DS. Based on the final volume of the FS after 1h, it is concluded, that the conductivity increase in the FS occurs mainly because of up-concentrating. The starting volume of FS was $0.5 \mathrm{~L}$ for all filtrations and volume of transported water was $22.8 \mathrm{~mL}$ (volume decrease for $4.6 \%$ ) and $21.8 \mathrm{~mL}$ (volume decrease for $4.4 \%$ ) for $\mathrm{NaCl}$ and for $\mathrm{MgCl}_{2}$, while using blue and green dye mixture the volume decrease was $21.7 \mathrm{~mL}(4.3 \%)$, and $19 \mathrm{~mL}(3.8 \%)$. While conductivity increase was $4.3 \%$ (from $9.4 \mathrm{mS} / \mathrm{cm}$ to $9.8 \mathrm{mS} / \mathrm{cm}$ ), 3.2\% (from $9.37 \mathrm{mS} / \mathrm{cm}$ to $9.67 \mathrm{mS} / \mathrm{cm}$ ), $8.19 \%$ (from 9.52 to $10.3 \mathrm{mS} / \mathrm{cm}$ ), and $2.4 \%$ (from 9.62 to $9.85 \mathrm{mS} / \mathrm{cm}$ ) in the $\mathrm{FS}$ using $\mathrm{NaCl}$, $\mathrm{MgCl}_{2}$, blue and green dye mixture as DS, respectively. We have to consider the deviations in mass changes due to mass balance and air in tubes. Nevertheless, the obtained \% increase in conductivity of the FS corresponds to the \% volume decrease except for the blue dye mixture DS. For this case the difference is $3.9 \%$ between up-concentrating and conductivity increase suggesting some salt passage from DS to FS.

When using DI water as FS (\#1), reverse salt flux can be calculated using Eq. 2. Results for $J_{w}$ and $J_{s}$ (secondary y-axis) are presented on Fig. 4. For dye mixtures, it was assumed that only salt passes through the membrane, therefore, the conductivity measurements were converted to concentrations of $\mathrm{Na}_{2} \mathrm{SO}_{4}$ for green dye mixture, and mixture of $\mathrm{Na}_{2} \mathrm{SO}_{4}$ and $\mathrm{Na}_{2} \mathrm{CO}_{3}$ salts for the blue dye mixture. 


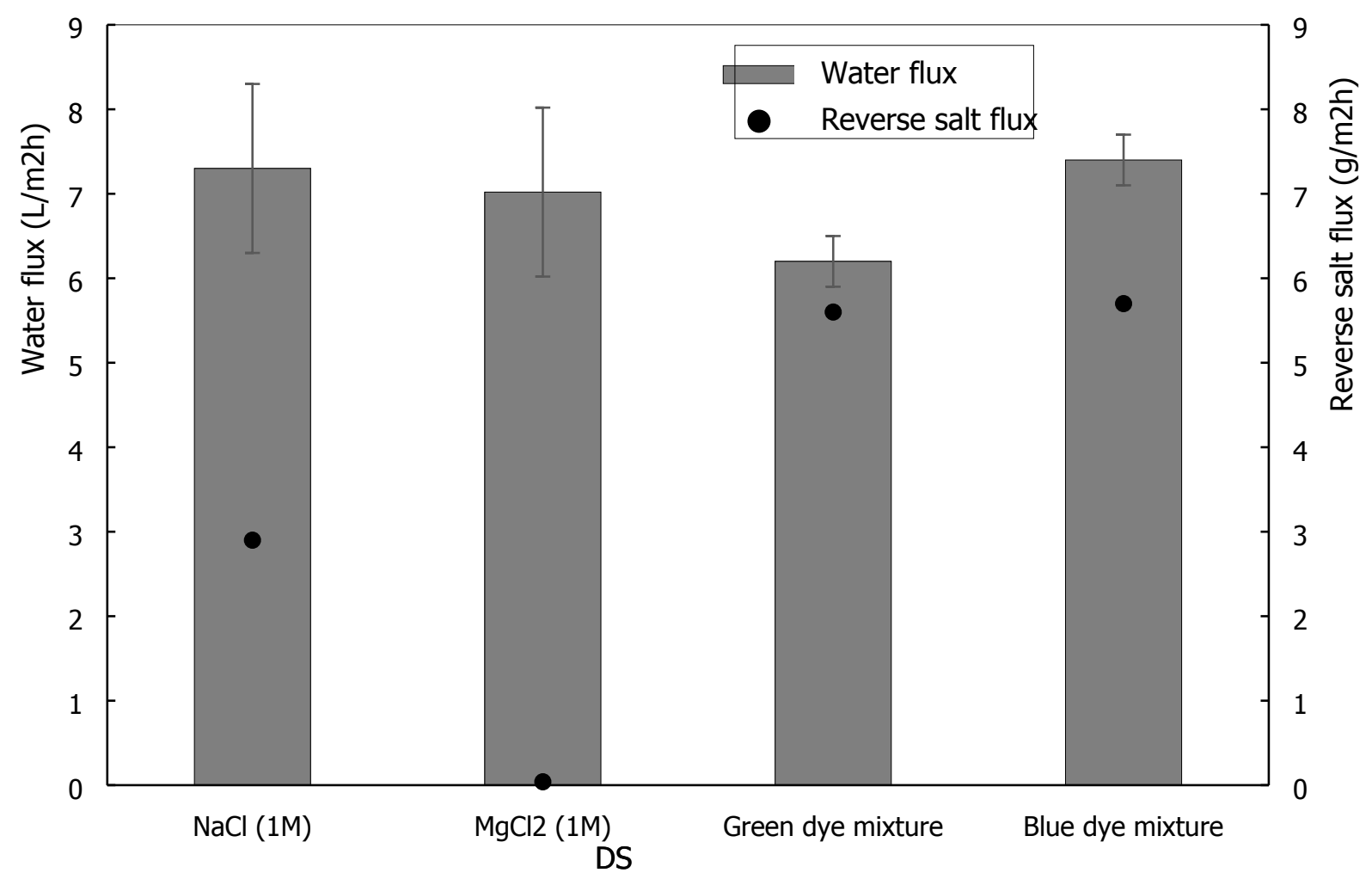

Fig. 4. Average water flux, $J_{w}$ in $1 \mathrm{~h}$ running and reverse salt flux, $J_{s}$ using DI water as FS.

Reverse salt flux is usually increasing with increasing water flux, nevertheless, the type/characteristics of DS also has impact on salt permeation. $\mathrm{MgCl}_{2}$ compared with $\mathrm{NaCl}$ has lower $J_{s}$. Namely, $J_{s}$ for $\mathrm{MgCl}_{2}$ and $\mathrm{NaCl}$ were 0.04 and $2.9 \mathrm{~g} / \mathrm{m}^{2} \mathrm{~h}$, respectively. However, much higher values are achieved with dye mixtures where obtained values were $5.6 \mathrm{~g} / \mathrm{m}^{2} \mathrm{~h}$ (green dye mixture) and $5.7 \mathrm{~L} / \mathrm{m}^{2} \mathrm{~h}$ (blue dye mixture). No detectable dyestuff permeated through the FO membrane, the rejection of dyes and other coloured agents in dye mixture were $100 \%$ in both experiments as determined by spectrophotometry. It has been reported that in FO mode, a DS with lower aqueous diffusivity, larger ion/molecule size and higher viscosity will cause more severe dilutive ICP, leading to lower water flux (Zhao and Zou, 2011). When using green and blue dye mixtures as DS the dominant inorganic salt is $\mathrm{Na}_{2} \mathrm{SO}_{4}$ which generally has a lower diffusivity in the support layer and higher viscosity compared to $\mathrm{NaCl}$ (Zhao and Zou, 2011). The observed higher reverse salt flux for the two dye DS (about $2 \mathrm{x}$ compared to $\mathrm{NaCl}$ ) is consistent with increased ICP however the lower water flux for dye DS is not significantly lower than for $\mathrm{NaCl}$ as $\mathrm{DS}$.

Pre-determined concentrations of green and blue dye mixtures were selected based on final desired concentrations of the FS, where the desired final volume of FS (concentrated 
wastewater) was $50 \%$ of the initial volume as the resulting wastewater concentration will still allow for discharge to the municipal wastewater treatment plant. Fig. 5 shows $J_{w}(t)$ during the up-concentration of textile wastewater with FO process using green and blue dye mixtures as a DS. The volume of DS and FS were $0.5 \mathrm{~L}$. FO experiment with $0.6 \mathrm{M} \mathrm{NaCl}$ was performed for comparison.

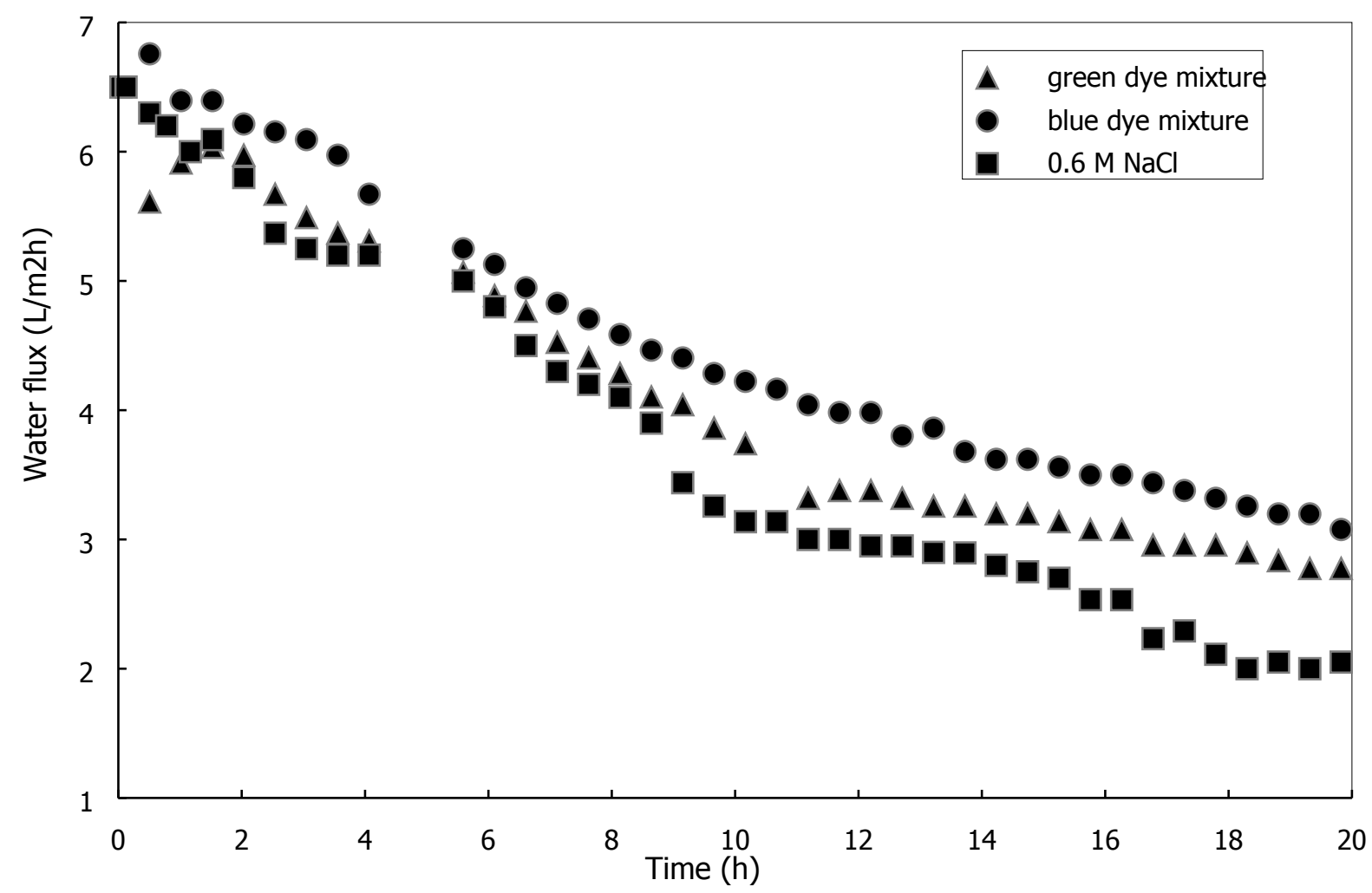

Fig. 5. Water flux, $J_{w}$ during textile wastewater concentration using dye mixture as a DS; (•) blue dye mixture, $(\boldsymbol{\Delta})$ green dye mixture, and () $0.6 \mathrm{M} \mathrm{NaCl}$.

Within $21 \mathrm{~h}, 299.2 \mathrm{~mL}$ and $332.1 \mathrm{~mL}$ of water permeated through FO membrane from textile wastewater into the DS using green dye mixture and blue dye mixture as a DS, respectively. Water recovery reached $50 \%$ after $18.33 \mathrm{~h}$ and $16.03 \mathrm{~h}$ for green and blue dye mixtures respectively. Water flux decreased about $50 \%$ and this could be due to a gradually lowered osmotic pressure difference across the membrane (arising from the dilution of DS and concentration of FS) or due to membrane fouling. In order to resolve this a membrane integrity test was performed, see Fig. 6. First, used membranes were cleaned with DI water as a FS and DS at higher flow rate, in order to flush accumulated particles on the membrane. Integrity test was running for $1 \mathrm{~h}$, using DI water as a $\mathrm{FS}$ and $1 \mathrm{M} \mathrm{NaCl}$ as DS. Second, chemical cleaning of membranes (see Table 3) was performed, following the same FO experiment with DI water and 
$1 \mathrm{M} \mathrm{NaCl}$. For both dye mixtures $J_{w}$ from used membranes was similar to the $J_{w}$ of virgin membranes (between 7 and $7.5 \mathrm{~L} / \mathrm{m}^{2} \mathrm{~h}$ ) after chemical cleaning.

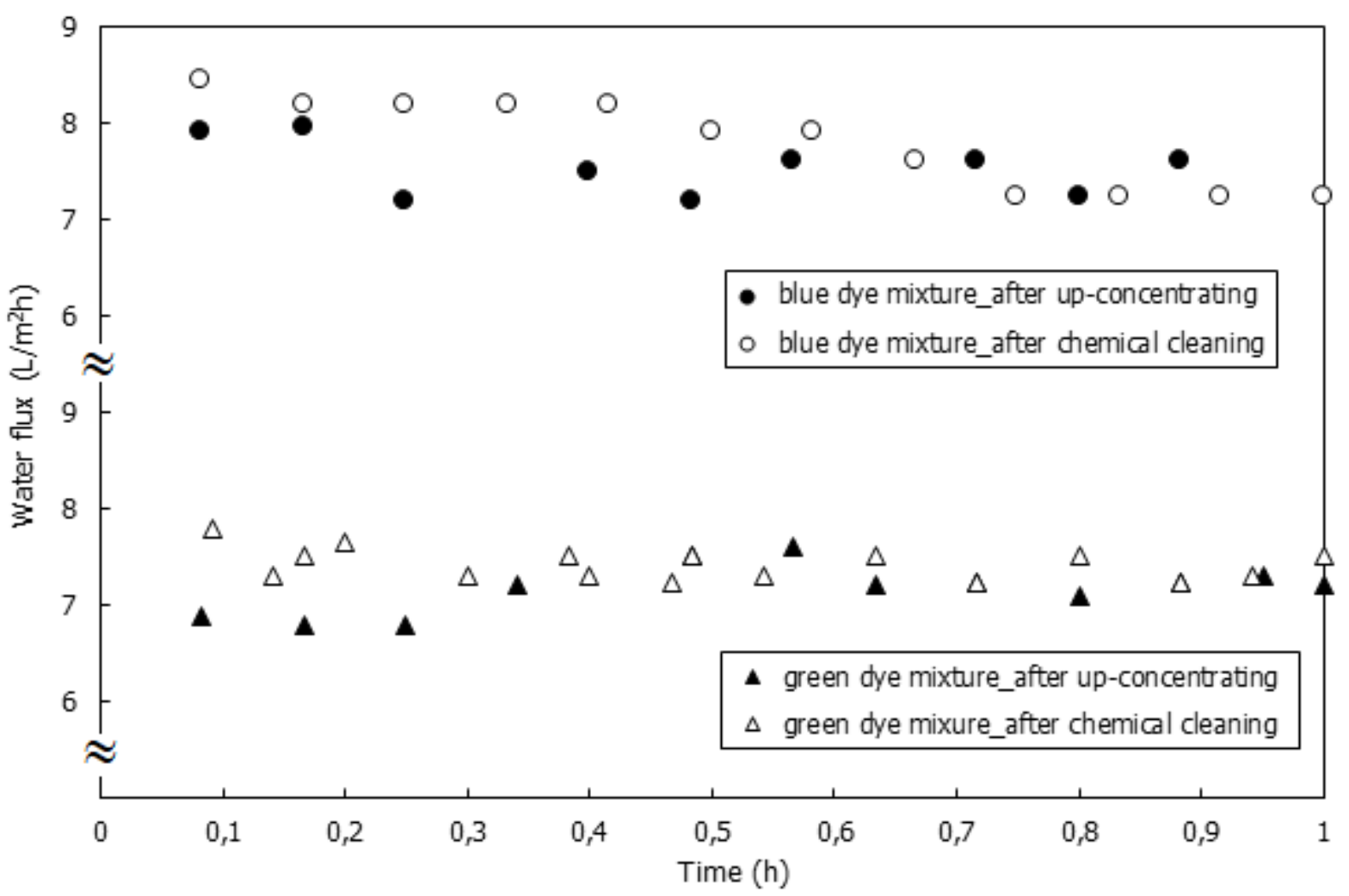

Fig. 6. Water flux, $J_{w}$ obtained using DI water as FS and $1 \mathrm{M} \mathrm{NaCl}$ as DS in integrity test directly after up concentrating and cleaning processes for green and blue dye mixtures.

Thus no fouling occurred within $21 \mathrm{~h}$ of concentrating wastewater and the observed decrease in $J_{w}$ was a result of DS dilution only.

\subsection{FO with constant -concentration DS and real textile wastewater as FS}

In order to evaluate the fouling propensity, an experiment with the DS kept at a constant concentration (and low reverse salt flux) and real textile wastewater as FS was performed, where the decrease in $J_{w}$ can be ascribed to the fouling process see Fig. 7,. The raw wastewater used had a conductivity of $2.2 \mathrm{mS} / \mathrm{cm}$ and $\mathrm{pH}$ of 9.02 . The COD, TDS and TSS concentrations were $2,862 \mathrm{mg} \mathrm{O}_{2} / \mathrm{L}, 1,944 \mathrm{mg} / \mathrm{L}$ and $144 \mathrm{mg} / \mathrm{L}$, respectively. $\mathrm{MgCl}_{2}$ was used as DS providing a lower reverse salt flux compared to $\mathrm{NaCl}$, see Fig. 4. The feed volume at the beginning was 3L and additionally, the fresh FS was added two times: after $8.5 \mathrm{~h}$, and after $15.6 \mathrm{~h}$. Since the DS conductivity stayed constant, $J_{w}$ could decrease due to impurities accumulating on the membrane surface thereby increasing the membrane resistance. The driving force might also decline because of the increased osmotic pressure in FS as it got up-concentrated, Nevertheless, 
$J_{w}$ was constantly decreasing during the time $(21 \mathrm{~h})$ even after FS dilution due to addition of new batches of textile wastewater, thus significant fouling occurred.

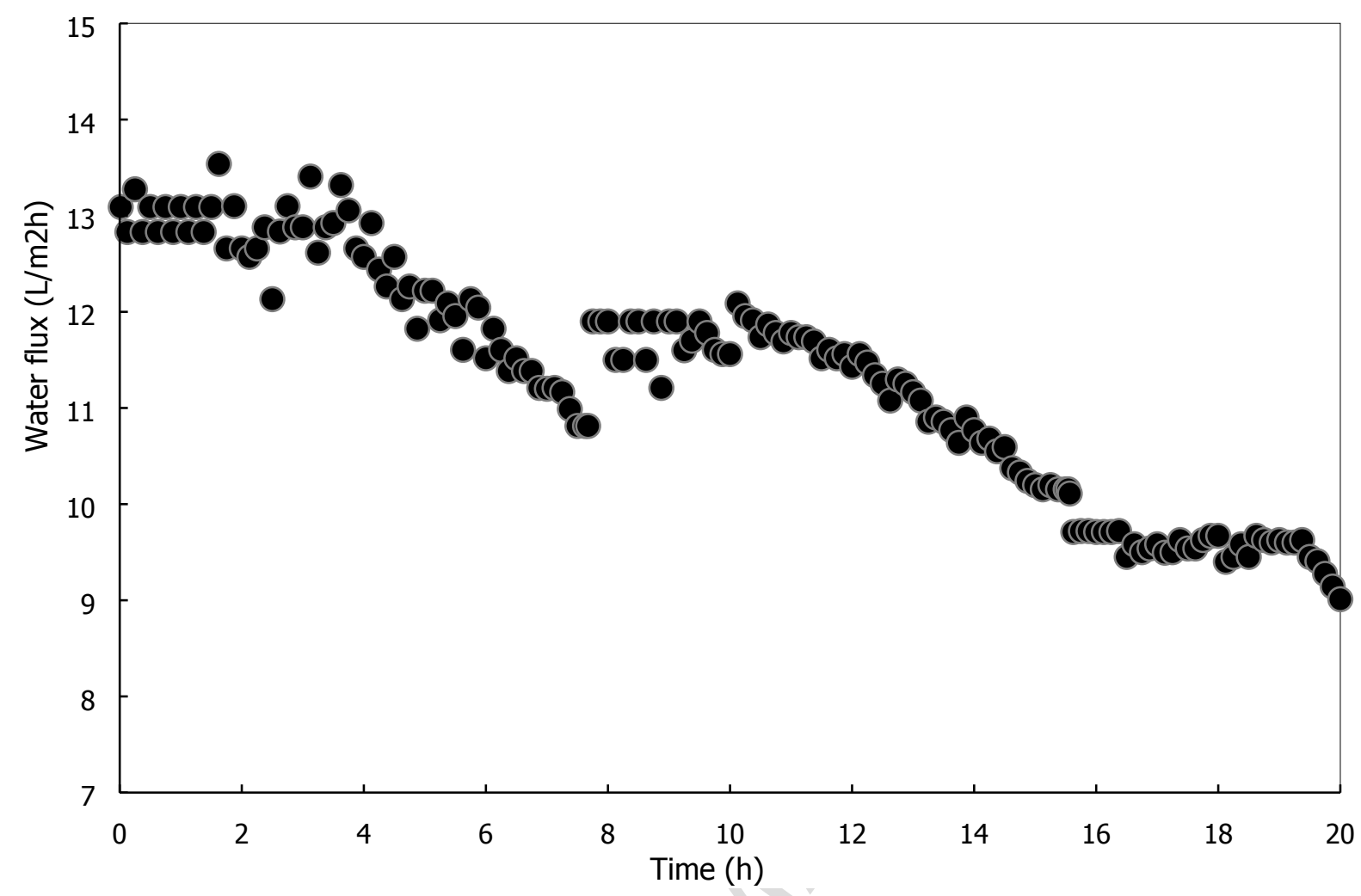

Fig. 7. Water flux versus time for an FO filtration where real textile wastewater was used as FS and $2 \mathrm{M} \mathrm{MgCl}_{2}$ as DS.

After the filtration, membrane was taken out of the chamber and chemical cleaning at $\mathrm{pH} 11$ and $\mathrm{pH} 2$ (see Table 3) was performed. In order to determine dominant resistance and flux recovery, DI water and $2 \mathrm{M} \mathrm{MgCl}_{2}$ were used as a feed and DS, with volumes of $3 \mathrm{~L}$ and $1 \mathrm{~L}$, respectively. The concentration of DS was maintained constant during the FO process. $J_{w}$ versus time in a $1 \mathrm{~h}$ experiment with virgin, fouled, and cleaned membrane is presented in Fig. 8 with $J_{s}$ values given on secondary y-axis. 


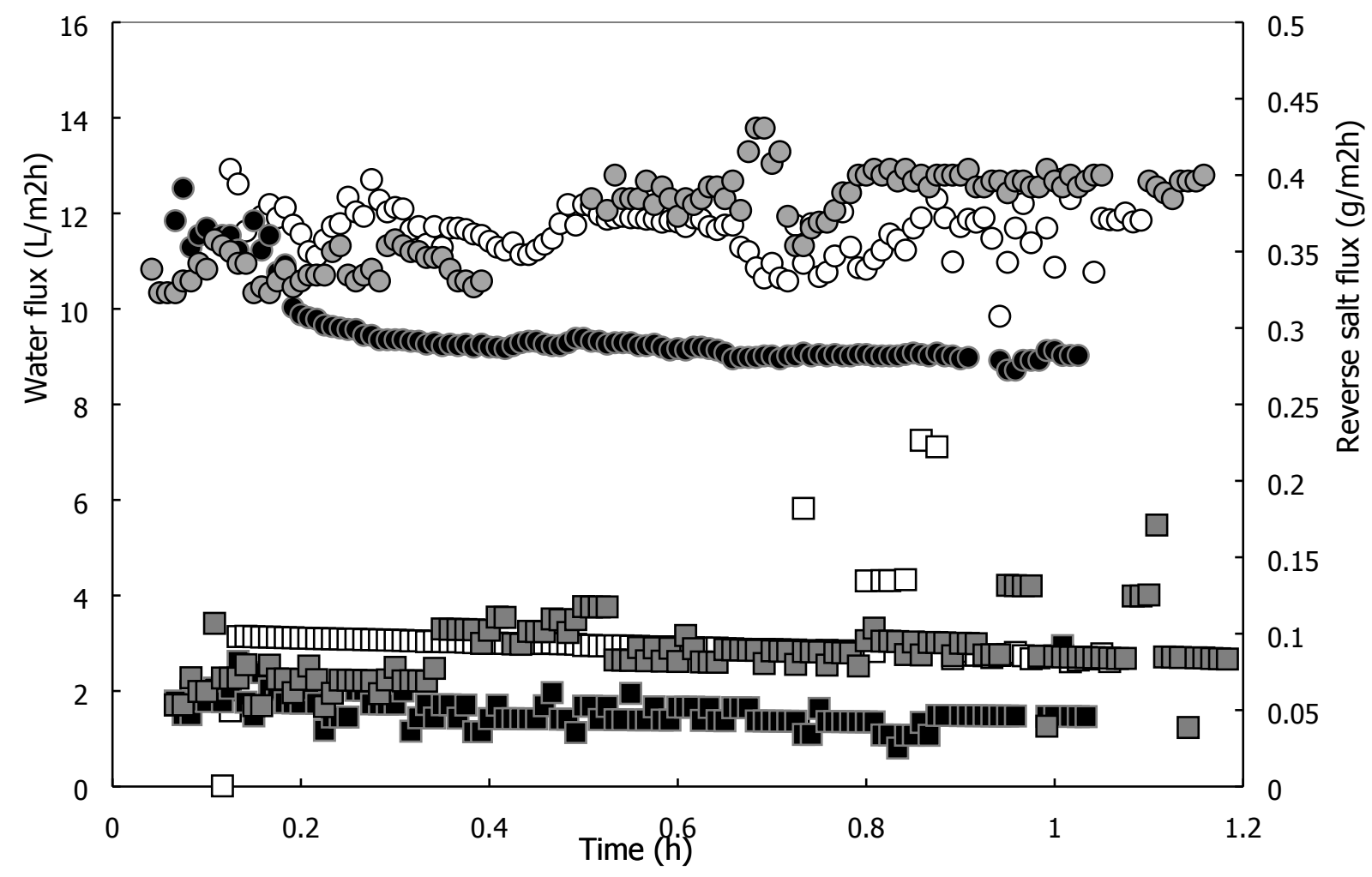

Fig. 8. Water flux, $J_{w}$ of virgin (O), fouled (•), and cleaned (O) membrane and reverse salt flux, $J_{s}$ of virgin ( $\square$ ), fouled ( $\square$ ), and cleaned $(\square)$ membrane.

The results showed that water flux after cleaning returned to the initial virgin membrane values, while $J_{s}$ stayed $0.1 \mathrm{~g} / \mathrm{m}^{2} \mathrm{~h}$. Taking together, the established chemical cleaning was efficient and flux recovery was achieved in $100 \%$. Similar results have been obtained from FO treatment of sewage from aeration tank of a local municipal wastewater treatment plant. (Gao et al., 2018). Specifically, this study investigated fouling on FO membranes (HTI, USA) made from cellulose triacetate with embedded polyester support (CTA-ES). After $25 \mathrm{~h}$ of sewage concentrating they achieved $90 \%-96 \%$ flux recovery by physical and chemical cleaning.

The results in Fig. 8 show that fouling was reversible. Using Eqns. 5 and 6 the type and relative contribution of each resistance can be quantified. Based on the average values of $J_{w}$ and $J_{s}$ in 1h running (presented in Table 6) the membrane resistances can be determined, see Table 7. 
Table 6. Average $J_{w}$ and $J_{s}$ obtained in $1 \mathrm{~h}$ filtration on virgin, fouled and chemically cleaned membrane.

\begin{tabular}{lcc}
\hline & $J_{w}\left(\mathrm{~L} / \mathrm{m}^{2} \mathrm{~h}\right)$ & $J_{s}\left(\mathrm{~g} / \mathrm{m}^{2} \mathrm{~h}\right)$ \\
\hline Virgin & 11.6 & 0.09 \\
Used & 9.2 & 0.04 \\
Cleaned & 12.5 & 0.08 \\
\hline
\end{tabular}

From Table 7 it is confirmed, that irreversible fouling did not occur and also that the main resistance contribution to the total resistance is from the FO membrane itself ( $79 \%)$ with the rest arising from the reversible resistance (21\%).

Table 7. Membrane resistances of FO filtration of real textile wastewater.

\begin{tabular}{lc}
\hline Type of resistance & Value $\left(10^{15} \mathrm{~m}^{-1}\right)$ \\
\hline$R_{m}$ & 6.9740 \\
$R_{\text {rev }}$ & 1.8193 \\
$R_{\text {irrev }}$ & 0 \\
$R_{t}$ & 8.7933 \\
\hline
\end{tabular}

These results demonstrate that membrane fouling is not an essential drawback in FO-based treatment of raw textile wastewater.

Rejection of wastewater pollutants is an important factor when evaluating concentrating efficiency and water recovery. To analyse this further, samples were taken from the FS before and after the FO process. Rejection of TDS, TSS and COD was calculated using Eq. 7 and results are given in Table 8 . The FO membrane achieved different rejection for various recovery rates, particular in COD removal, which decreased with increasing recovering rate. Nevertheless, the COD rejection was $>94 \%$ till $55 \%$ of recovery. The rejection of TDS, TSS, $\mathrm{Zn}^{2+}$, and $\mathrm{SO}_{4}{ }^{2-}$ was $>99 \%$. A good rejection of macromolecules, and trace organics compounds have been also presented by several studies (Kong et al., 2015, Sun et al., 2016, Xie et al., 2018).

Table 8. Rejection of parameters in FS at different recovery rates.

\begin{tabular}{cccccc}
\hline Recovery rate (\%) & TDS (\%) & TSS (\%) & COD (\%) & $\mathrm{SO}_{4}^{2}(\%)$ & $\mathrm{Zn}^{2+}(\%)$ \\
\hline 70.8 & 99 & 100 & 74 & 99 & 99 \\
56.1 & 99 & 100 & 95 & 99 & 99 \\
33.8 & 99 & 100 & 97 & 99 & 99 \\
\hline
\end{tabular}




\subsection{Membrane surface characterisation}

Membrane surface characteristics (zeta potential, contact angle, SEM and ATR-FTIR) were performed on virgin, fouled, and cleaned membrane. Electrokinetic measurements are presented on Fig. 9.

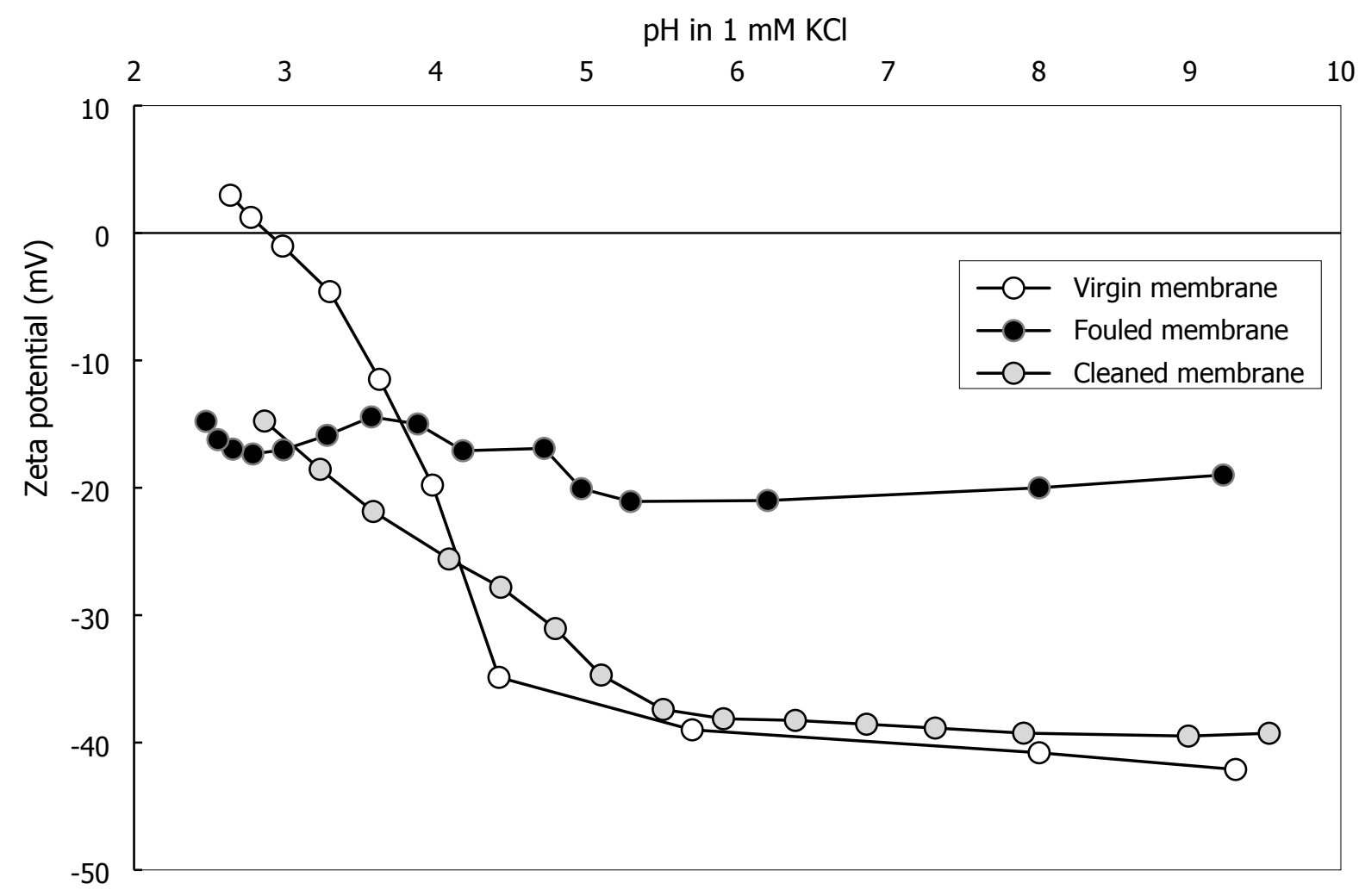

Fig. 9. $\mathrm{pH}$ dependence of zeta potential for $\mathrm{FO}$ membranes when using $1 \mathrm{mM} \mathrm{KCl}$ for electrolyte solution.

Fig. 9 shows the zeta potential of virgin, fouled and cleaned FO membranes against $\mathrm{pH}$ values. Generally, the negative ZP range confirms the presence of dissociable acidic functional groups on the membrane surface. For the virgin membrane the plateau of the curve (complete dissociation of acidic functional groups) is around $-40 \mathrm{mV}$ and isoelectric point, IEP (the $\mathrm{pH}$ value at which the net charge and zeta potential is 0 ) is around $\mathrm{pH} 3$. The fouled membrane becomes less negative in zeta potential with the plateau shifted from $-40 \mathrm{mV}$ to $-20 \mathrm{mV}$ when compared with virgin membrane but the IEP was not reached. The plateau of the cleaned membrane returns to the plateau level of the virgin membrane $(-40 \mathrm{mV})$ and shows more negative zeta potential and thus less hydrophilic character in comparison with the fouled membrane. When comparing the part of the curve in the $\mathrm{pH}$ range 3-5, an increase in slope is observed compared with the curve for the fouled membrane. The measurements demonstrate the existence of a fouling layer on the membrane surface and also success of the cleaning 
procedure as evidenced by the shift of the values for the cleaned membrane back to virgin membrane values for $\mathrm{pH}>5$.

The changes in zeta-potential are mirrored in the contact angle measurements presented in Fig. 10. Membranes were examined with MiliQ water and depending on the sample, average values were based on 3-8 drops using the tangent method (Marmur, 2006).

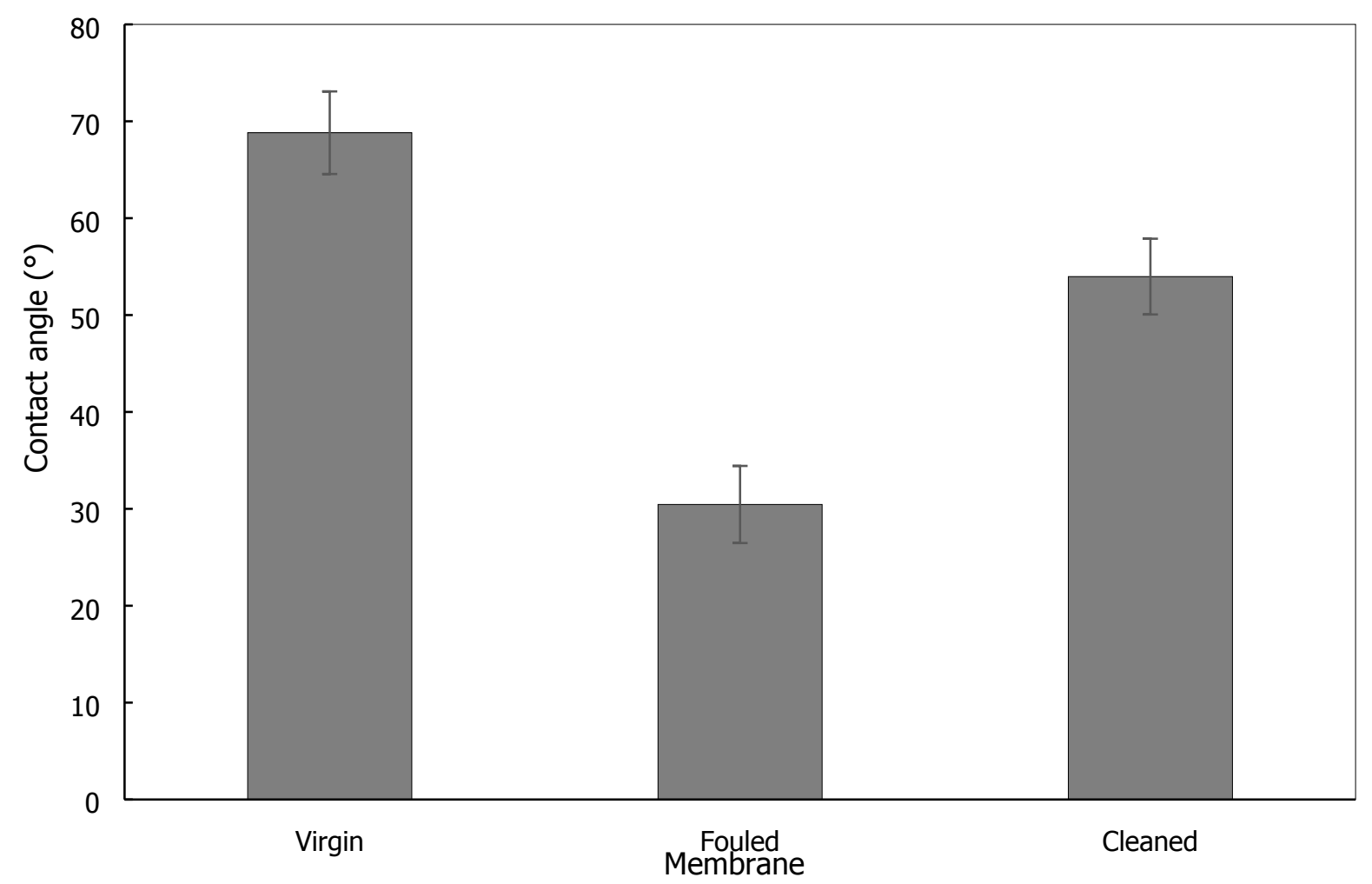

Fig. 10. Contact angles of the active layer surface of virgin, fouled, and cleaned membranes.

Contact angle values for virgin, fouled and cleaned membranes were $69^{\circ}, 30^{\circ}$, and $54^{\circ}$, respectively, and show the hydrophilic nature of the virgin/cleaned membrane surface.

In order to gain further insight, membrane morphology was characterised from SEM micrographs of the top surface (active layer) of virgin, fouled and cleaned membranes, see Fig. 11. The fouling layer almost disappeared after cleaning, as confirmed by the absence of significant morphological difference between virgin and cleaned membranes. 


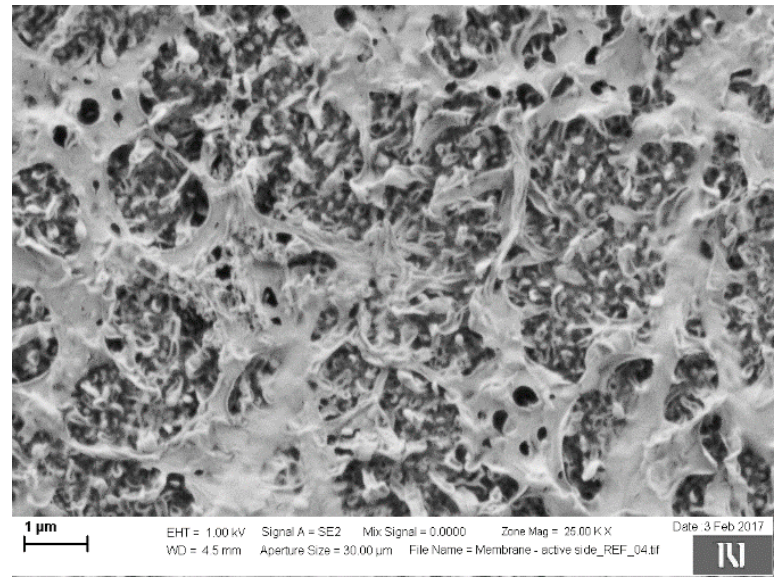

(a)

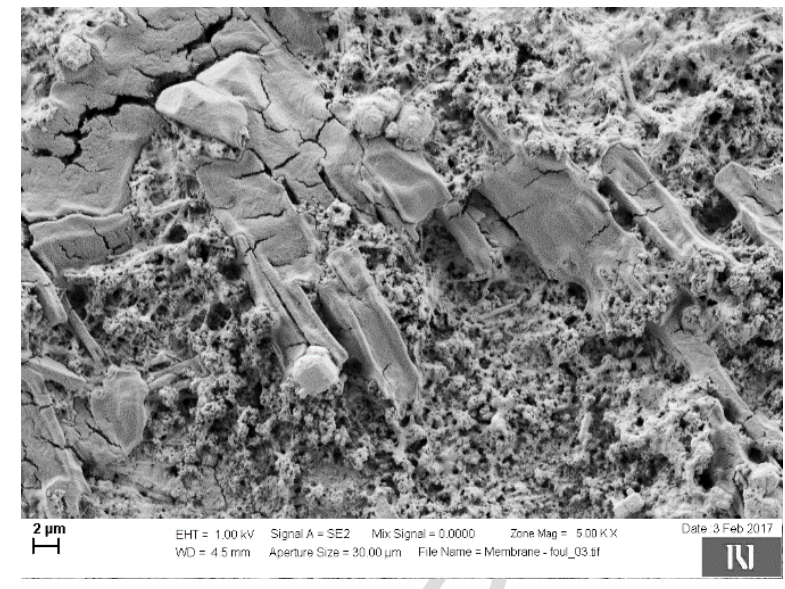

(b)

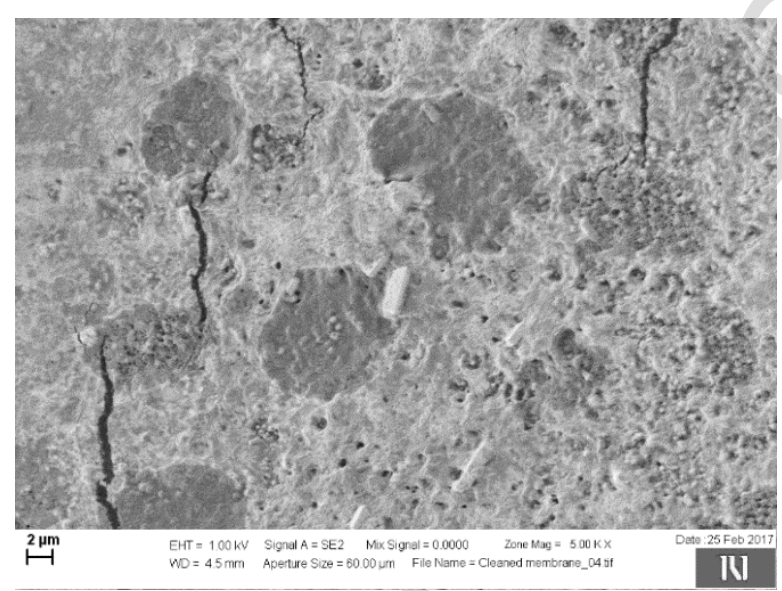

(c)

Fig. 11. SEM images of (a) virgin, (b) fouled and (c) cleaned FO membrane's active layer.

The ATR-FTIR analysis in Fig. 12 shows a characteristic peak around $3350 \mathrm{~cm}^{-1}$, attributable to $\mathrm{OH}$ groups on the fouled membrane. This signal, absent in the virgin membrane, is reduced in the cleaned membrane. Thus the ATR-FTIR analysis revealed that part of the fouling may be irreversible, but this had no effect on performance judged from the membrane resistance analysis, see Table 7. Two other peaks are seen at 1610 and $1577 \mathrm{~cm}^{-1}$ that could correspond to functional group amide (N-H) and is detected only on fouled membrane. The peak at $2300 \mathrm{~cm}^{-1}$ indicates the presence of nitrile groups $(\mathrm{C} \equiv \mathrm{N})$ which seems to disappear after chemical cleaning. 


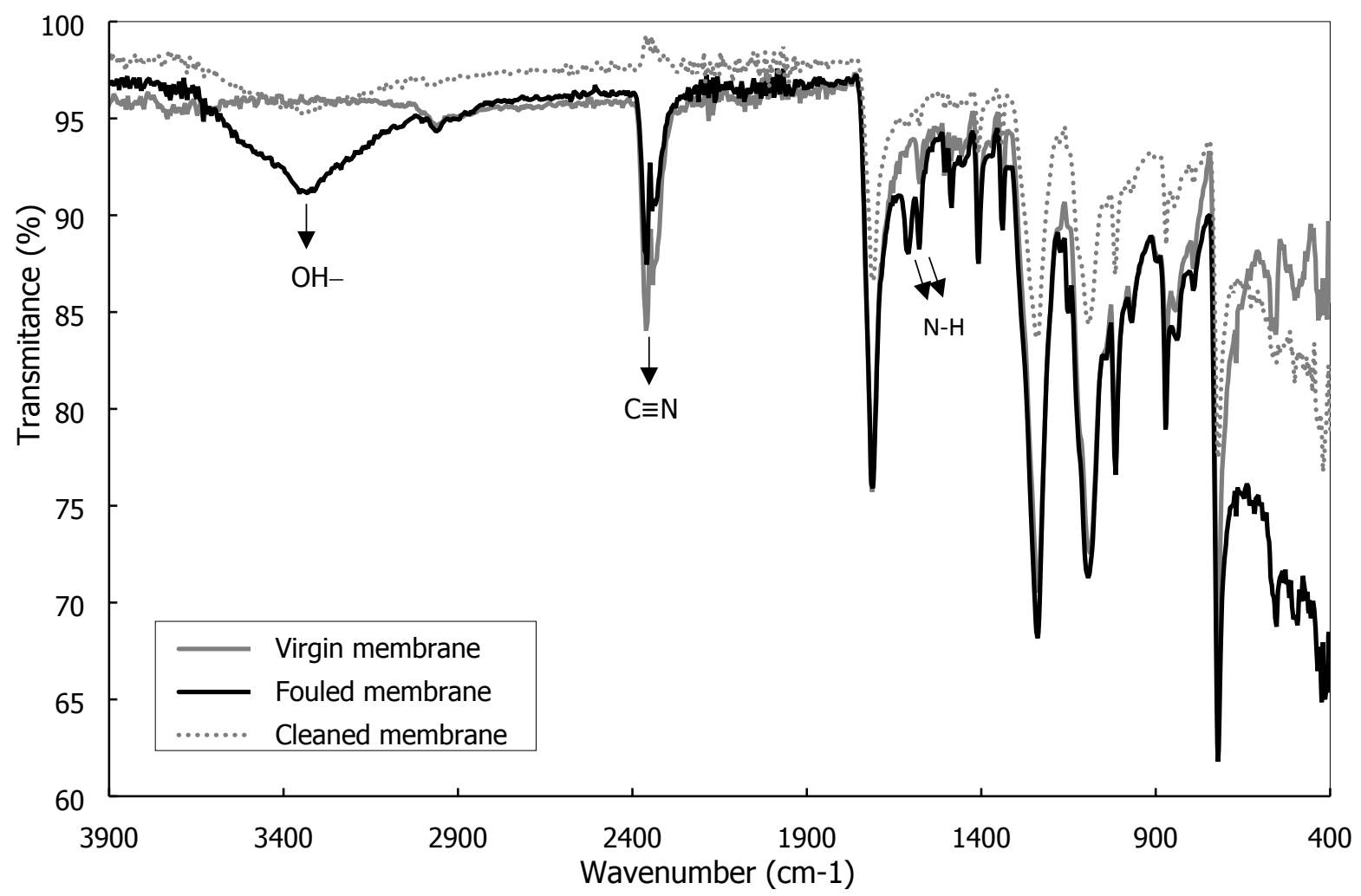

Fig. 12. ATR-FTIR analysis of virgin, fouled and cleaned membrane.

Taken together, membrane surface characterisation with ZP, contact angle, SEM and ATRFTIR, analysis confirmed that membrane surface changed after being exposed to textile wastewater and concentrated dye mixtures. However, there were no permanently changes on the FO membrane surface after chemical cleaning. The results confirm previous results that FO membranes with incorporated aquaporins exhibits chemical resistance in membrane cleaning procedure, maintaining a stable flux and high salt rejection (Li et al., 2017).

\subsection{Economic feasibility study}

The feasibility of integrating the FO process in textile wastewater treatment was analysed for two different scenarios, see Fig. 13. One using a concentrated salt solution (e.g. $\mathrm{MgCl}_{2}$ ) as DS requiring an additional re-concentration step (e.g. via reverse osmosis), and one using concentrated dye mixtures as DS eliminating the need for a re-concentration step. 


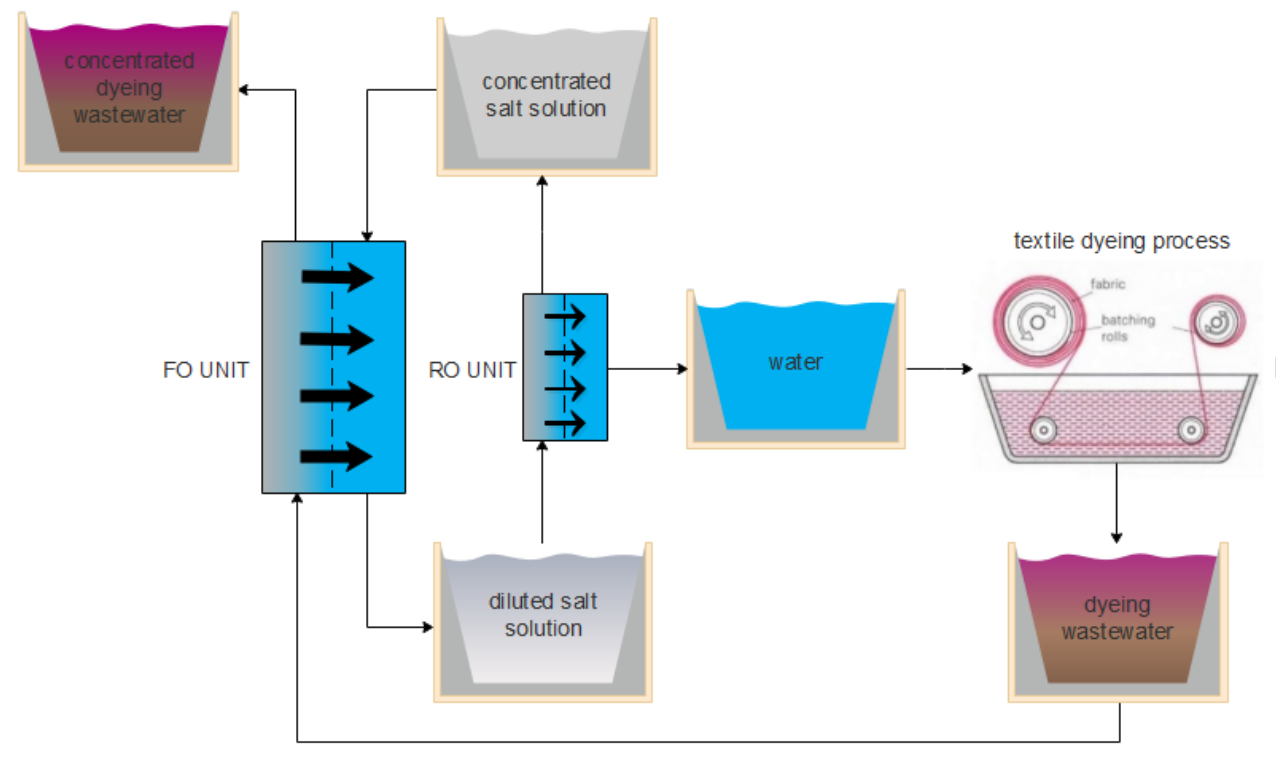

(a)

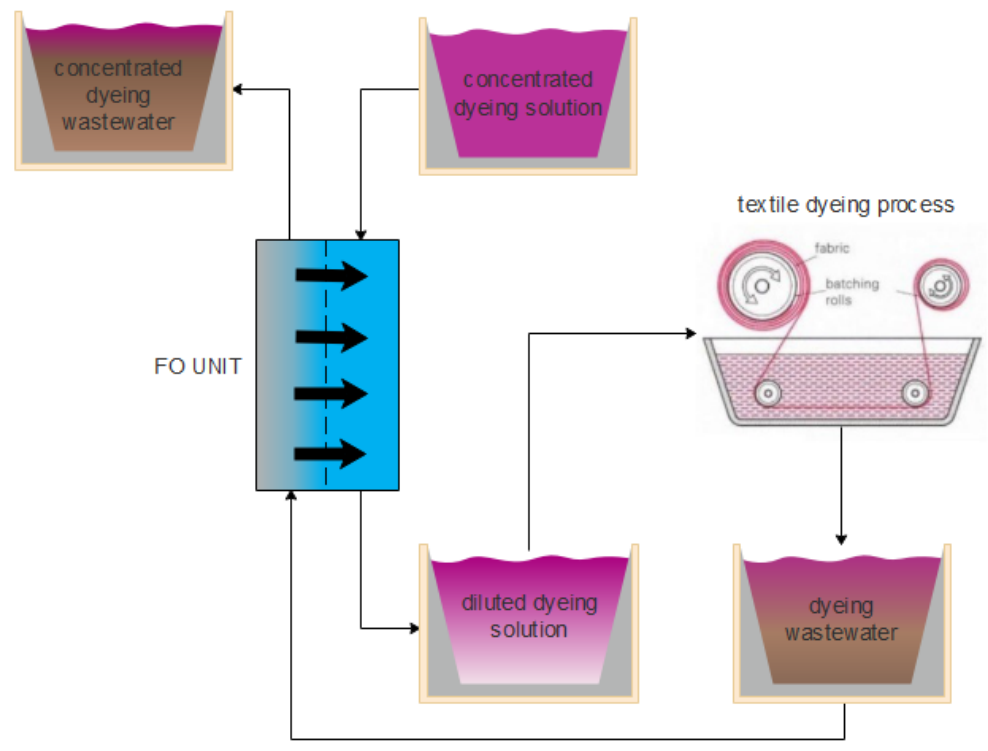

(b)

Fig. 13. Scheme of FO process integrated in textile wastewater treatment plant, (a) using inorganic salt as a DS, (b) using dye mixture as a DS.

In Fig. 13a the additional RO unit for regeneration of salt solution represents an investment cost and also contribute to a higher operational cost. By using chemical agents (dye mixtures) from the production line, this additional regeneration step for DS is eliminated, see Fig. 13b.

The following analysis was based on a daily production of industrial wastewater of $90 \mathrm{~m}^{3}$ /day at A\&E Europe d.o.o., Maribor, Slovenia which currently is collected and treated with coagulation/flocculation before discharge to the municipal wastewater treatment plant. 
TSS, $\mathrm{SO}_{4}{ }^{2-}$ concentration and colour content were selected based on annual physical/chemical parameters monitored by the factory as these are the parameters with concentrations near to limiting values and it was calculated, that with dewatering for $50 \%$ these will still be below limiting values for discharge. Therefore, the recovery of implemented FO-RO and FO process was set to $50 \%$ for further calculations of operational costs.

Table 9 presents calculated values for operational conditions of FO-RO and FO units. The calculations were made based on mass balance (Eq.8-Eq.11) and with an estimated amount of wastewater suitable for further treatment around $33,000 \mathrm{~m}^{3} / y e a r$. The experimental data $\left(J_{w}\right.$ and $J_{s}$ ) for FO membrane was provided by performing $\mathrm{FO}$ experiments using $1 \mathrm{M} \mathrm{NaCl}$ and dye mixtures as DS. The water permeability and salt rejection for RO membrane is representative for desalination membranes. Salt permeation data was used to determine salt lost through FO and RO membrane on daily basis (Eq.15 and Eq.16).

Table 9. Operational conditions for FO using different DS.

\begin{tabular}{|c|c|c|c|c|}
\hline Parameter & Unit & $\begin{array}{c}\text { Blue dye } \\
\text { mixture as DS }\end{array}$ & $\begin{array}{c}\text { Green dye } \\
\text { mixture as DS }\end{array}$ & $\begin{array}{c}0.6 \mathrm{M} \mathrm{NaCl} \\
\text { as DS }\end{array}$ \\
\hline Proposed operating conditions & & 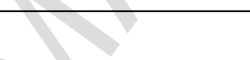 & & \\
\hline FO Recovery & $\%$ & 50 & 50 & 50 \\
\hline RO Recovery & 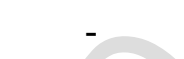 & - & - & 50 \\
\hline Feed Inlet flow rate & $\mathrm{m}^{3} /$ day & 90 & 90 & 90 \\
\hline Daily operating duration & hour & 12 & 12 & 12 \\
\hline Total volume of treated water & $\mathrm{m}^{3} /$ day & 45 & 45 & 45 \\
\hline \multicolumn{5}{|l|}{ Calculated operating conditions } \\
\hline Feed Outlet flow rate & $\mathrm{m}^{3} /$ day & 45 & 45 & 45 \\
\hline Draw Inlet flow rate & $\mathrm{m}^{3} /$ day & 45 & 45 & 45 \\
\hline Draw Outlet flow rate & $\mathrm{m}^{3} /$ day & 90 & 90 & 90 \\
\hline Concentration of DS & $\mathrm{mol} / \mathrm{L}$ & $\begin{array}{l}\text { Concentrated } \\
\text { blue dye } \\
\text { mixture }\end{array}$ & $\begin{array}{l}\text { Concentrated } \\
\text { green dye } \\
\text { mixture }\end{array}$ & $0.6 \mathrm{M} \mathrm{NaCl}$ \\
\hline Concentration of DS Outlet & $\mathrm{mol} / \mathrm{L}$ & $\begin{array}{c}\text { Diluted for } \\
50 \%\end{array}$ & $\begin{array}{l}\text { Diluted for } \\
50 \%\end{array}$ & $0.3 \mathrm{M} \mathrm{NaCl}$ \\
\hline FO pump power consumption & $\mathrm{kWh} / \mathrm{m}^{3}$ & 0.15625 & 0.15625 & 0.15625 \\
\hline RO pump power consumption & $\mathrm{kWh} / \mathrm{m}^{3}$ & - & - & 0.6194 \\
\hline \multicolumn{5}{|c|}{ Experimental conditions for FO \& RO membrane } \\
\hline$J_{w}$ average (FO) & $\mathrm{L} / \mathrm{m}^{2} \mathrm{~h}$ & 4.8 & 3.8 & 6.3 \\
\hline$J_{s}$ average $(\mathrm{FO})$ & $\mathrm{g} / \mathrm{m}^{2} \mathrm{~h}$ & 1.44 & 1.14 & \\
\hline Water permeability (RO) & $\mathrm{L} / \mathrm{m}^{2} \mathrm{~h}$ bar & - & - & 2 \\
\hline $\mathrm{NaCl}$ rejection $(\mathrm{RO})$ & $\%$ & - & - & 98.5 \\
\hline Number of FO modules & module & 40 & 50 & 30 \\
\hline RO membrane area required & $\mathrm{m}^{2}$ & - & - & 31.5 \\
\hline
\end{tabular}


Salt lost through FO membrane

Salt lost through RO membrane $\mathrm{kg} /$ day

$\mathrm{kg} / \mathrm{day}$
13.5

13.5

0.59

The number of FO membrane modules was calculated based on daily feed flow rate, membrane area per module, $\%$ of recovery, and average water flux through the FO membrane (Eq. 13). The calculation of RO membrane area, Eq. 14, takes into account required daily permeate flow, water RO membrane permeability, operating pressure, 36 bar (depends on osmotic pressure of feed), and water flux. The FO pump power consumption includes two pumps (for DS and for FS) with assumed pump efficiency of $80 \%$ and pump operating pressure of 3 bar (Eq. 12).

Table 10 indicates operational costs considering membrane costs, and DS replenishment. The calculation for electricity costs is based on industry consumer rates in Slovenia (for 2017).

Table 10. The specified operational costs for FO and FO-RO process.

\begin{tabular}{|c|c|c|c|c|}
\hline Parameter & Unit & $\begin{array}{c}\text { Blue dye } \\
\text { mixture as a DS }\end{array}$ & $\begin{array}{c}\text { Green dye } \\
\text { mixture as a DS }\end{array}$ & $\begin{array}{c}0.6 \mathrm{M} \mathrm{NaCl} \\
\text { as a DS }\end{array}$ \\
\hline FO membrane & $€ / \mathrm{m}^{2}$ & 31.62 & 31.62 & 31.62 \\
\hline RO membrane & $€ / \mathrm{m}^{2}$ & - & - & 3.16 \\
\hline Electrical cost for FO pump & $€ / \mathrm{m}^{3}$ & 081 & 0.0081 & 0.0081 \\
\hline Electrical cost for RO pump & $€ / \mathrm{m}^{3}$ & & - & 0.0322 \\
\hline $\begin{array}{l}\text { Amortized FO membrane } \\
\text { replacement }\end{array}$ & $€ / \mathrm{m}^{3}$ & & 0.448 & 0.269 \\
\hline $\begin{array}{l}\text { Amortized RO membrane } \\
\text { replacement }\end{array}$ & $€ / \mathrm{n}$ & & & 0.002 \\
\hline Cost of DS replenishment & $E / \mathrm{II}^{2}$ & _ & - & 0.04 \\
\hline Total & $€ / \mathrm{m}^{3}$ & 0.37 & 0.46 & 0.35 \\
\hline
\end{tabular}

Assumptions were made in amortizations calculations (Eq. 17) for an interest rate of 5.3\%, and a membrane life span of 5 years. The sum of total operational costs includes electrical cost for FO and RO pumps, cost for DS, and amortization for membrane replacement.

The process using dye solution instead of salt resulted in similar operational costs. The highest impact on these calculations has the required amount of FO membranes, because the cost of FO membranes is significantly higher compared to the RO membranes, currently. Therefore, lower costs can be obtained with a DS that could provide higher $J_{w}$. Nevertheless, it needs to be considered that chemical agents for membrane cleanings are not included. This would increase OPEX especially for the FO-RO process, because of the fouling tendency of RO membranes. Additional costs of chemical agents for RO membrane cleaning and ant-scaling chemical 
products are assumed to be $0.09 € / \mathrm{m}^{3}$ (Petrinic et al., 2015). Therefore, operational costs for FO-RO increase to $0.44 € / \mathrm{m}^{3}$.

Nevertheless, the FO-RO system could be economically feasible, since the cost of tap water is the same compared to the calculated operational cost of produced water. The same process (FORO) was evaluated based on economic feasibility and compared with traditional desalination RO process by Wan and Chun (Wan and Chung, 2018). They conclude that FO-RO could reduce both OPEX and CAPEX of seawater desalination.

In conclusion the results indicate that the proposed FO based treatment system would provide $50 \%$ less wastewater volume that needs to be transported on municipal wastewater treatment plant. Thus, $50 \%$ of produced water could be reused in dye mixture solution preparation or as clean water (cost of tap water is $0.47 € / \mathrm{m}^{3}$, currently, however, it is assumed that the cost would increase in next years, because of water scarcity worldwide) for toilets, machine washing in the production, etc. 


\section{Conclusion}

The performance parameters of the FO process $\left(J_{w}, J_{s}\right)$ showed constant values during textile wastewater concentration with performance recovery after chemical cleaning. The FO membranes became reversible fouled after $21 \mathrm{~h}$ of wastewater concentrating and could be easily cleaned. Additionally, the FO process demonstrates an effective rejection of dye stuff, (100\%) and $>95 \%$ rejection in COD achieved, and $>99 \%$ rejection of contaminants such as TDS, TSS, $\mathrm{Cu}^{2+}$ and $\mathrm{Zn}^{2+}$, and $\mathrm{SO}_{4}{ }^{2-}$. Evaluated operational costs for $\mathrm{FO}$ and FO-RO process showed an economic benefit of implementation and reducing wastewater volumes by $50 \%$ to be disposed to the municipal wastewater treatment plant. Even though, neglecting capital costs, the benefits of treatment reuse system for such high consumer of fresh water will keep increasing, because of environmental pollution and water scarcity. Therefore, FO technology could indeed be a solution for textile wastewater up-cycling/reuse and secure a cleaner (less water consuming) textile production in the future.

\section{Acknowledgements}

The authors would like to acknowledge financial support from the Slovenian Research Agency (Javna Agencija za Raziskovalno Dejavnost RS) for their Project No. 1000 - 14 - 0552, and support from the Innovation Fund Denmark via the IBISS project and MEMENTO project. 


\section{References}

Achilli, A., Cath, T. Y., Marchand, E. A. Childress, A. E., 2009. The forward osmosis membrane bioreactor: A low fouling alternative to MBR processes. Desalination 239, 10-21.

Chekli, L., Phuntsho, S., Shon, H. K., Vigneswaran, S., Kandasamy, J. Chanan, A., 2012. A review of draw solutes in forward osmosis process and their use in modern applications. Desalin. Water Treat. 43, 167-184.

Chung, T.-S., Li, X., Ong, R. C., Ge, Q., Wang, H. Han, G., 2012. Emerging forward osmosis (FO) technologies and challenges ahead for clean water and clean energy applications. Current Opinion in Chemical Engineering 1, 246-257.

Dasgupta, J., Sikder, J., Chakraborty, S., Curcio, S. Drioli, E., 2015. Remediation of textile effluents by membrane based treatment techniques: A state of the art review. Journal of Environmental Management 147, 55-72.

Gao, Y., Fang, Z., Liang, P. Huang, X., 2018. Direct concentration of municipal sewage by forward osmosis and membrane fouling behavior. Bioresource Technology 247, 730-735.

Ge, Q., Ling, M. Chung, T.-S., 2013. Draw solutions for forward osmosis processes: Developments, challenges, and prospects for the future. J. Membr. Sci. 442, 225-237.

Ge, Q., Su, J., Chung, T.-S. Amy, G., 2011. Hydrophilic Superparamagnetic Nanoparticles: Synthesis, Characterization, and Performance in Forward Osmosis Processes. Ind. Eng. Chem. Res. 50, 382-388.

Ge, Q., Wang, P., Wan, C. Chung, T.-S., 2012. Polyelectrolyte-Promoted Forward Osmosis-Membrane Distillation (FO-MD) Hybrid Process for Dye Wastewater Treatment. Environmental Science \& Technology 46, 6236-6243.

Han, G., Liang, C.-Z., Chung, T.-S., Weber, M., Staudt, C. Maletzko, C., 2016. Combination of forward osmosis (FO) process with coagulation/flocculation (CF) for potential treatment of textile wastewater. Water Research 91, 361-370.

Hao, O. J., Kim, H. Chiang, P.-C., 2000. Decolorization of Wastewater. Critical Reviews in Environmental Science and Technology 30, 449-505.

Hickenbottom, K. L., Hancock, N. T., Hutchings, N. R., Appleton, E. W., Beaudry, E. G., Xu, P. Cath, T. Y., 2013. Forward osmosis treatment of drilling mud and fracturing wastewater from oil and gas operations. Desalination 312, 60-66.

Kong, F.-X., Yang, H.-w., Wu, Y.-q., Wang, X.-m. Xie, Y. F., 2015. Rejection of pharmaceuticals during forward osmosis and prediction by using the solution-diffusion model. Journal of Membrane Science 476, 410-420.

Li, Z., Valladares Linares, R., Bucs, S., Fortunato, L., Hélix-Nielsen, C., Vrouwenvelder, J. S., Ghaffour, N., Leiknes, T. Amy, G., 2017. Aquaporin based biomimetic membrane in forward osmosis: Chemical cleaning resistance and practical operation. Desalination 420, 208-215.

Liang, C.-Z., Sun, S.-P., Li, F.-Y., Ong, Y.-K. Chung, T.-S., 2014. Treatment of highly concentrated wastewater containing multiple synthetic dyes by a combined process of coagulation/flocculation and nanofiltration. Journal of Membrane Science 469, 306-315.

Liang, C.-Z., Sun, S.-P., Zhao, B.-W. Chung, T.-S., 2015. Integration of Nanofiltration Hollow Fiber Membranes with Coagulation-Flocculation to Treat Colored Wastewater from a Dyestuff Manufacturer: A Pilot-Scale Study. Industrial \& Engineering Chemistry Research 54, 11159-11166.

Lutchmiah, K., Verliefde, A. R. D., Roest, K., Rietveld, L. C. Cornelissen, E. R., 2014. Forward osmosis for application in wastewater treatment: A review. Water Research 58, 179-197.

Marmur, A., 2006. Soft contact: measurement and interpretation of contact angles. Soft Matter 2, 1217. 
Mi, B. Elimelech, M., 2010a. Gypsum Scaling and Cleaning in Forward Osmosis: Measurements and Mechanisms. Environ. Sci. Technol. 44, 2022-2028.

Mi, B. Elimelech, M., 2010b. Organic fouling of forward osmosis membranes: Fouling reversibility and cleaning without chemical reagents. J. Membr. Sci. 348, 337-345.

Mohammadi, T., Madaeni, S. S. Moghadam, M. K., 2002. Investigation of membrane fouling. Desalination 153, 155-160.

Petrinic, I., Korenak, J., Povodnik, D. Hélix-Nielsen, C., 2015. A feasibility study of UF/ RO-based wastewater treatment and reuse in the metal finishing industry. Journal of Cleaner Production 101, 292300 .

Sun, Y., Tian, J., Zhao, Z., Shi, W., Liu, D. Cui, F., 2016. Membrane fouling of forward osmosis (FO) membrane for municipal wastewater treatment: A comparison between direct FO and OMBR. Water Research 104, 330-339.

Valladares Linares, R., Li, Z., Abu-Ghdaib, M., Wei, C.-H., Amy, G. Vrouwenvelder, J. S., 2013. Water harvesting from municipal wastewater via osmotic gradient: An evaluation of process performance. J. Membr. Sci. 447, 50-56.

Verma, A. K., Dash, R. R. Bhunia, P., 2012. A review on chemical coagulation/flocculation technologies for removal of colour from textile wastewaters. Journal of Environmental Management 93, 154-168.

Wan, C. F. Chung, T.-S., 2018. Techno-economic evaluation of various RO+PRO and RO+FO integrated processes. Applied Energy 212, 1038-1050.

Wang, L., Zhang, W., Chu, H. Dong, B., 2016. Forward osmosis filtration for removal of organic foulants: Effects of combined tannic and alginic acids. Water Research 91, 251-263.

Wang, Q., Luan, Z., Wei, N., Li, J. Liu, C., 2009. The color removal of dye wastewater by magnesium chloride/red mud (MRM) from aqueous solution. Journal of Hazardous Materials 170, 690-698.

Xie, M., Luo, W., Guo, H., Nghiem, L. D., Tang, C. Y. Gray, S. R., 2018. Trace organic contaminant rejection by aquaporin forward osmosis membrane: Transport mechanisms and membrane stability. Water Research 132, 90-98.

Xie, M., Nghiem, L. D., Price, W. E. Elimelech, M., 2013. A Forward Osmosis-Membrane Distillation Hybrid Process for Direct Sewer Mining: System Performance and Limitations. Environ. Sci. Technol. 47, 13486-13493.

Zhang, Q., Jie, Y. W., Loong, W. L. C., Zhang, J., Fane, A. G., Kjelleberg, S., Rice, S. A. McDougald, D., 2014. Characterization of biofouling in a lab-scale forward osmosis membrane bioreactor (FOMBR). Water Research 58, 141-151.

Zhang, S., Wang, P., Fu, X. Chung, T.-S., 2014. Sustainable water recovery from oily wastewater via forward osmosis-membrane distillation (FO-MD). Water Research 52, 112-121.

Zhang, X., Ning, Z., Wang, D. K. Diniz da Costa, J. C., 2014. Processing municipal wastewaters by forward osmosis using CTA membrane. Journal of Membrane Science 468, 269-275.

Zhang, X., Pan, J. H., Du, A. J., Fu, W., Sun, D. D. Leckie, J. O., 2009. Combination of one-dimensional $\mathrm{TiO} 2$ nanowire photocatalytic oxidation with microfiltration for water treatment. Water Research 43, 1179-1186.

Zhao, S. Zou, L., 2011. Relating solution physicochemical properties to internal concentration polarization in forward osmosis. Journal of Membrane Science 379, 459-467. 